\title{
Copper Corroles: the Question of Noninnocence
}

\author{
Kristine Pierloot, ${ }^{*}$ Hailiang Zhao, and Steven Vancoillie \\ Department of Chemistry, University of Leuven, Celestijnenlaan 200F, B-3001 Heverlee-Leuven, Belgium
}

Received May 3, 2010

\begin{abstract}
In this paper, the results are presented from a comparative study of the electronic and geometric structure of copper correles by means of either density functional theory (DFT, using both pure and hybrid functionals) and multiconfigurational ab initio methods, starting from either a complete active space (CASSCF) or restricted active space (RASSCF) reference wave function and including dynamic correlation by means of second-order perturbation theory (CASPT2/RASPT2). DFT geometry optimizations were performed for the lowest singlet and triplet states of copper corrole, both unsubstituted and meso-substituted with three phenyl groups. The effect of saddling on the electronic structure was investigated by comparing the results obtained for planar $\left(C_{2 v}\right)$ and saddled $\left(C_{2}\right)$ structures. With DFT, the origin of the saddling distortion is found to be dependent on the applied functional: covalent $\mathrm{Cu} 3 d$-corrole $\pi$ interactions with pure functionals (BP86, OLYP), antiferromagnetic exchange coupling between an electron in the corrolate $\left(C_{2}\right) b$ type $\pi$ orbital, and an unpaired Cu $3 d$ electron with hybrid functionals (B3LYP, PBE0). The CASPT2 results essentially confirm the suggestion from the hybrid functionals that copper corroles are noninnocent, although the contribution of diradical character to the copper-corrole bond is found to be limited to $50 \%$ or less. The lowest triplet state is calculated at $0-10 \mathrm{kcal} / \mathrm{mol}$ and conform with the experimental observation (variable temperature NMR) that this state should be thermally accessible.
\end{abstract}

\section{Introduction}

Corroles are porphyrin-related macrocycles that have been the focus of ample attention in the past few years, ${ }^{1-4}$ mainly because of their coordination chemistry, showing unique and intriguing features that are clearly distinguishable from those of porphyrins. Just like porphyrins, corroles are 18-electron aromatic macrocycles, the difference being that corroles have a direct link between two pyrrole rings and, when fully deprotonated, are trianionic ligands. The formal oxidation state of a coordinated metal in corrole derivatives is one higher than that of the corresponding metalloporphyrinates, and often exceptionally high for the metal in question, for

*Corresponding author. Fax: +32 163279 92. E-mail: Kristin.Pierloot@ chem.kuleuven.be.

(1) Paolesse, R. In The Porphyrin Handbook; Kadish, K. M., Smith, K. M., Guilard, R., Eds.; Academic Press: San Diego, 2000; Vol. 2, pp 201-232.

(2) Gross, Z.; Gray, H. B. Comm. Inorg. Chem. 2006, 27, 61-72.

(3) Aviv, I.; Gross, Z. Chem. Commun. 2007, 20, 1987-1999.

(4) Aviv-Harel, I.; Gross, Z. Chem.-Eur. J. 2009, 15, 8382-8394.

(5) Vogel, E.; Will, S.; Tilling, A. S.; Neumann, L.; Lex, J.; Bill, E.; Trautwein, A. X.; Wieghardt, K. Angew. Chem., Int. Ed. 1994, 33, 731-735. (6) Will, S.; Lex, J.; Vogel, E.; Schmickler, H.; Gisselbrecht, J.; Haubtmann,

C.; Bernard, M.; Gross, M. Angew. Chem., Int. Ed. Engl. 1997, 36, 357-361.

(7) Ghosh, A.; Wondimagegn, T.; Parusel, A. B. J. J. Am. Chem. Soc. 2000, 122, 5100-5104.

(8) Meier-Callahan, A. E.; Gray, H. B.; Gross, Z. Inorg. Chem. 2000, 39, 3605-3607.

(9) Gross, Z.; Gray, H. B. Adv. Synth. Catal. 2004, 346, 165-170.

(10) Simkhovich, L.; Gross, Z. Inorg. Chem. 2004, 43, 6316-6318.

(11) Harischandra, D. N.; Zhang, R.; Newcomb, M. J. Am. Chem. Soc. 2005, 127, 13776-13777.

(12) Edwards, N. Y.; Eikey, R. A.; Loring, M. I.; Abu-Omar, M. M. Inorg. Chem. 2005, 44, 3700-3708. example, $\mathrm{Cu}^{\mathrm{III}}, \mathrm{Fe}^{\mathrm{IV}}, \mathrm{Fe}^{\mathrm{V}}, \mathrm{Mn}^{\mathrm{V}}, \mathrm{Cr}^{\mathrm{V}}, \mathrm{Mn}^{\mathrm{VI}}, \mathrm{Cr}^{\mathrm{VI}}{ }^{5-16}$ This is an intriguing feature, as unusually high oxidation states have also been proposed for some reactive intermediates in biological reactions involving heme enzymes. ${ }^{17-20}$ For this reason, the electronic structure of metallocorrolates has over the last few years been the focus of ample attention. Moreover, speculation that the corrole may rather have a noninnocent character, that is, bind as a one-electron oxidized dianionic radical instead of a closed-shell trianion, has given an additional boost to the research in this field. ${ }^{21-25}$ Corroles have

(13) Wasbotten, I.; Ghosh, A. Inorg. Chem. 2006, 45, 4910-4913.

(14) Golubkov, G.; Gross, Z. Angew. Chem., Int. Ed. 2003, 42, 4507-4510.

(15) Golubkov, G.; Gross, Z. J. Am. Chem. Soc. 2005, 127, 3258-3259.

(16) Hocking, R. K.; DeBeer George, S.; Gross, Z.; Walker, F. A.; Hodgson, K. O.; Hedman, B.; Solomon, E. I. Inorg. Chem. 2009, 48, 16781688 .

(17) Shaik, S.; Kumar, D.; de Visser, S. P.; Altun, A.; Thiel, W. Chem. Rev. 2005, 105, 2279-2328.

(18) Pan, Z. Z.; Wang, Q.; Horner, X. S. J. H.; Newcomb, M. J. Am. Chem. Soc. 2009, 131, 2621-2628.

(19) Shaik, S.; Cohen, S.; Wang, Y.; Chen, H.; Kumar, D.; Thiel, W. Chem. Rev. 2010, 110, 947-1017.

(20) Chen, H.; Song, J.; Lai, W.; Wu, W.; Shaik, S. J. Chem. Theory Comput. 2010, 6, 940-953.

(21) Walker, F. A.; Licoccia, S.; Paolesse, R. J. Inorg. Biochem. 2006, 100, $810-837$.

(22) Bröring, M.; Brégier, F.; Cónsul Tejero, E.; Hell, C.; Holthausen, M. C. Angew. Chem., Int. Ed. 2007, 46, 445-448.

(23) Ye, S.; Tuttle, T.; Bill, E.; Simkhovich, L.; Gross, Z.; Thiel, W.; Neese, F. Chem.-Eur. J. 2008, 14, 10839-10851.

(24) Roos, B. O.; Veryazov, V.; Conradie, J.; Taylor, P. R.; Ghosh, A. J. Phys. Chem. B 2008, 112, 14099-14102.

(25) Alemayehu, A. B.; Gonzalez, E.; Hansen, L. K.; Ghosh, A. Inorg. Chem. 2009, 48, 7794-7799. 
also been studied for applications in several fields, and a recent exhaustive review ${ }^{3}$ illustrates their potential applications. These macrocycles and the related metal complexes were applied in oxidation catalysis ( $\mathrm{Fe}, \mathrm{Mn}, \mathrm{Cr}$ ), reduction catalysis ( $\mathrm{Cr}, \mathrm{Mn}, \mathrm{Fe})$, group transfer catalysis ( $\mathrm{Rh}, \mathrm{Fe})$, sensors (Co), dye-sensitized solar cells ( $\mathrm{Ga}, \mathrm{Sn})$, and medicinal applications (free bases, Ga).

Copper corroles are characterized by a diamagnetic ground state. Until a few years ago, they were generally considered as typical low-spin copper(III) complexes. This assignment was first proposed ${ }^{6}$ on the basis of X-ray diffraction data, indicating copper-nitrogen bond lengths $(1.804-1.907 \AA)$ in the range characteristic for copper(III) complexes. Temperaturedependent ${ }^{1} \mathrm{H}$ NMR data pointed to the existence of a thermally accessible paramagnetic state, which was identified as a triplet copper(II) corrole $\pi$-radical cation. These findings were subsequently confirmed in several studies on copper corroles with different substituents. ${ }^{7,26-30}$ The first computational study, ${ }^{7}$ carried out on unsubstituted copper corrole by means of density functional theory (DFT with PW91 functional), also confirmed the $\mathrm{Cu}^{\mathrm{III}}$ closed-shell $\mathrm{d}^{8}$ character of the ground state, and identified the low-lying triplet state as originating from the excitation of an electron from the $b_{1}$ type corrole $\pi$ orbital into the empty $\mathrm{Cu} 3 \mathrm{~d}$ orbital. This picture remained generally accepted until three years ago, when a comparative X-ray diffraction (XRD) study of $\beta$-octaethyl5,15-diphenylcorrole with its 10-oxacorrole analogue pointed to very a similar molecular structure for both complexes, with copper-nitrogen distances that are even slightly shorter for the presumed $\mathrm{Cu}^{\mathrm{II}} 10$-oxacorrole than for the alleged $\mathrm{Cu}^{\mathrm{III}}$ corrole. $^{22}$ This result suggests that the effective oxidation state of copper in the corrole complex might in fact be closer to two than to three. This observation was further corroborated by spin-unrestricted DFT calculations (B3LYP functional), pointing to an open-shell singlet ground state built from antiferromagnetic coupling between $\mathrm{Cu}{ }^{\text {II }} \mathrm{d}^{9}$ and a singly occupied corrole $\pi$ orbital. An important point made by the authors of this work ${ }^{22}$ is that the antiferromagnetic coupling interaction is in fact the driving force for a saddling distortion of the corrolate ligand, allowing for attractive $\sigma-\pi$ interactions between the two orbitals involved in the coupling. Such a saddled structure is not exclusive for the strongly substituted $\beta$-octaethyl-5,15-diphenylcorrole studied in ref 22 (where it might have been ascribed to steric hindrance), but rather is a general feature of all copper corroles for which structures have been determined. ${ }^{6,25,27,29-31}$ A more recent X-ray crystallographic analysis of two sterically unhindered copper mesotriarylcorroles, combined with DFT calculations (OLYP functional), confirmed that saddling is indeed an inherent feature of copper corroles. ${ }^{25}$ Somewhat remarkably though, the saddled structures calculated with the OLYP functional

(26) Wasbotten, I. H.; Wondimagegn, T.; Ghosh, A. J. Am. Chem. Soc. 2002, 124, 8104-8116.

(27) Brückner, C.; Brinas, R. B.; Krause Bauer, J. A. Inorg. Chem. 2003, 42, 4495-4497.

(28) Steene, E.; Dey, A.; Ghosh, A. J. Am. Chem. Soc. 2003, 125, 1630016309

(29) Luobeznova, I.; Simkhovich, L.; Goldberg, I.; Gross, Z. Eur. J. Inorg. Chem. 2004, 1724-1732.

(30) Guilard, R.; Gros, C. P.; Barbe, J.-M.; Espinosa, E.; Jérôme, F.; Tabard, A.; Latour, J.-M.; Shao, J.; Ou, Z.; Kadish, K. M. Inorg. Chem. 2004, 43, 7441-7455.

(31) Ngo, T. H.; Puntoriero, F.; Nastasi, F.; Robeyns, K.; Meervelt, L. V.; Campagna, S.; Dehaen, W.; Maes, W. Chem. A Eur. J. 2010, 16, 5691-5705.

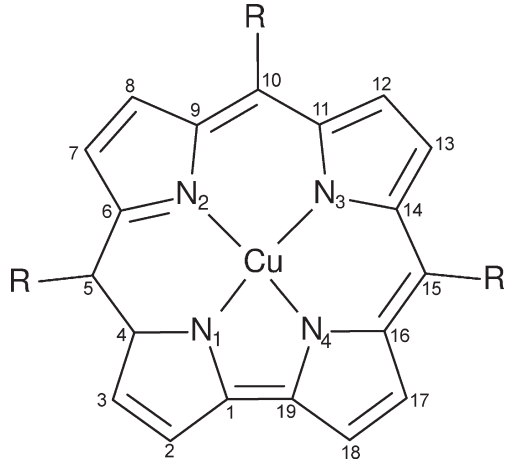

Figure 1. Calculated structures: $\mathrm{Cu}(\mathrm{C})(\mathrm{R}=\mathrm{H})$ and $\mathrm{Cu}(\mathrm{TPC})\left(\mathrm{R}=\mathrm{C}_{6} \mathrm{H}_{5}\right)$.

were found to have a closed-shell singlet ground state, that is, showing zero spin density at all points in space, rather than the (unphysical) spatial separation of positive and negative spin densities that is observed with $\mathrm{B}^{2} \mathrm{LYP}^{22}$ and that has become a hallmark of antiferromagnetic coupling in DFT. ${ }^{32-37}$ With the OLYP functional, the saddling inducing $\sigma-\pi$ interactions are instead manifested by a strongly delocalized HOMO, showing an almost equal mixture of $\mathrm{Cu} 3 \mathrm{~d}$ and corrole $\pi$ character.

In this work, theoretical calculations are reported for two copper corrole complexes, containing either unsubstituted corrole $(\mathrm{Cu}(\mathrm{C}))$ or meso-triphenyl corrole $(\mathrm{Cu}(\mathrm{TPC}))$ (Figure 1). A comparison is made between the results obtained from DFT with four different functionals, that is, the pure generalized gradient approximation (GGA) BP86 and OLYP, and two hybrid functionals B3LYP and PBE0, ${ }^{38-48}$ and from either the complete or restricted active space self-consistent field method (CASSCF or RASSCF), with dynamic correlation accounted for with second-order perturbation theory (CASPT2 or RASPT2). ${ }^{49,50}$ In order to get a more fundamental insight into the factors governing corrole noninnocence in relation to structural saddling, this issue will be investigated in two steps. First, we will look at the relative energies of the lowest singlet and triplet states in the planar structures of either $\mathrm{Cu}(\mathrm{C})$ or $\mathrm{Cu}(\mathrm{TPC})$. In a second step, the effect of saddling on the electronic structure is investigated.

(32) Bachler, V.; Olbrich, G.; Neese, F.; Wieghardt, K. Inorg. Chem. 2002, 41, 4179-4193.

(33) Herebian, D.; Wieghardt, K. E.; Neese, F. J. Am. Chem. Soc. 2003 125, 10997-11005.

(34) Neese, F. J. Phys. Chem. Solids 2004, 65, 781-785.

(35) Wasbotten, I.; Ghosh, A. Inorg. Chem. 2006, 45, 4914-4921.

(36) Cramer, C. C.; Truhlar, D. G. Phys. Chem. Chem. Phys. 2009, 11 , $10757-10816$

(37) Saito, T.; Kataoka, Y.; Nakanashi, Y.; Matsui, T.; Kitagawa, Y.; Kawakami, T.; Okumura, M.; Yamaguchi, K. Int. J. Quant. Chem. 2009, 109, 3649-3658.

(38) Dirac, P. A. M. Proc. R. Soc. (London) A 1929, 123, 714

(39) Slater, J. C. Phys. Rev. 1951, 81, 385

(40) Vosko, S. H.; Wilk, L.; Nusair, M. Can. J. Phys. 1980, 58, 1200

(41) Lee, C.; Yang, W.; Parr, R. G. Phys. Rev. B 1988, 37, 785.

(42) Perdew, J. P.; Wang, Y. Phys. Rev. B 1986, 33, 8822

(43) Becke, A. D. Phys. Rev. A 1988, 38, 3098.

(44) Becke, A. D. J. Chem. Phys. 1993, $98,5648$.

(45) Perdew, J. P.; Wang, Y. Phys. Rev. B 1992, 45, 13244.

(46) Perdew, J. P.; Burke, K.; Ernzerhof, M. Phys. Rev. Lett. 1996, 77, 3865

(47) Perdew, J. P.; Ernzerhof, M.; Burke, K. J. Chem. Phys. 1996, 105, 9982.

(48) Handy, N. C.; Cohen, A. J. Mol. Phys. 2001, 99, 403-412.

(49) Andersson, K.; Malmqvist, P.-A.; Roos, B. O. J. Chem. Phys. 1992 96, 1218.

(50) Malmqvist, P.-Å.; Pierloot, K.; Shahi, A. R. M.; Cramer, C. J.; Gagliardi, L. J. Chem. Phys. 2008, 128, 204109. 
A detailed discussion of the extent of diradical character in both structures is provided in Section 3.3.

\section{Calculational Details}

DFT geometry optimizations were performed with either the TURBOMOLE $5.10^{51}$ or Gaussian 03 code, ${ }^{52}$ using TZVP basis sets on all atoms. ${ }^{53}$ Four functionals were used: the pure GGA functionals BP8 $6^{38-40,42,43}$ and OLYP $\mathrm{P}^{41,48}$ and the hybrid functionals B3LYP ${ }^{38-41,43,44}$ and PBE0. ${ }^{38,39,45-47}$ Calculations were performed for the lowest states of triplet and singlet spin multiplicity of the molecules $\mathrm{Cu}(\mathrm{C})$ and $\mathrm{Cu}-$ (TPC) (Figure 1). For all states, the optimum geometry was found (and confirmed by frequency analyses) to have at least $C_{2}$ symmetry, corresponding to a saddled structure.

However, the discussion will start from a set of results obtained from DFT geometry optimizations on planar structures, obtained by enforcing $C_{2 v}$ symmetry. For $\mathrm{Cu}$ (TPC), the phenyl substituents were in these $C_{2 v}$ structures oriented perpendicular to the corrole plane. The planar $\mathrm{Cu}(\mathrm{C})$ structures obtained from B3LYP were subsequently used in an additional series of single-point test calculations, using a functional that starts from B3LYP, but in which the relative contribution of Hartree-Fock (HF) and Slater (S) exchange was systematically varied between $100 \%$ and $0 \%$ (the standard B3LYP functional containing $80 \% \mathrm{~S}$ and $20 \% \mathrm{HF}$ exchange).

In order to investigate the effect of saddling on the electronic structure, a saddling angle is defined as the average of the four (positive) out-of-plane angles of each of the $\mathrm{Cu}-\mathrm{N}$ bonds with respect to the $\mathrm{C}-\mathrm{Cu}-\mathrm{C}$ plane containing the two $\beta$-carbons belonging to the same five-ring as the considered $\mathrm{N}$, for example, $\mathrm{Cu}-\mathrm{N}_{1}$ and $\mathrm{C}_{1}-\mathrm{Cu}-\mathrm{C}_{2}$ in Figure 1. This out-of-plane angle, denoted as $\Omega$, was varied between $0-9 \operatorname{deg}$ for $\mathrm{Cu}(\mathrm{C})$ and between $0-13 \mathrm{deg}$ for $\mathrm{Cu}(\mathrm{TPC})$. A series of structures along the saddling distortion path were calculated by fixing $\Omega$ but optimizing all other structural parameters (within $C_{2}$ symmetry). For $\mathrm{Cu}(\mathrm{C})$, the structure with $\Omega=0$ deg exactly corresponds to the planar $C_{2 v}$ structure. However, for $\mathrm{Cu}(\mathrm{TPC})$ the phenyl rings are in the planar $C_{2}$ structure rotated with respect to the corrole plane, giving rise to a small but distinct energy gain (up to $2.5 \mathrm{kcal} / \mathrm{mol}$ ) with respect to the $C_{2 v}$ structure.

Single point CASSCF/CASPT2 ${ }^{49}$ and RASSCF/RASPT2 ${ }^{50}$ calculations were subsequently performed on the $C_{2 v}$ and $C_{2}$ DFT structures obtained with the PBE0 functional, making use of the MOLCAS 7.4 $4^{54,55}$ code. The choice of PBE0 structures is based on the observation (see next sections) that this functional gives the "best" structures (i.e., on average closest to experiment and giving rise to the lowest CASPT2 energy). This was also found in our previous studies ${ }^{56,57}$ on a series of $\mathrm{Fe}^{\mathrm{II}}$ complexes. All CASSCF/CASPT2 calculations were performed with atomic natural orbital (ANO) type basis sets. For copper and the corrole ligand, ANO-rcc basis sets ${ }^{58}$ were used, contracted as follows: $\mathrm{Cu}$ [7s6p5 d3f2g1h], N [4s3p2d1f], $\mathrm{C}[4 \mathrm{~s} 3 \mathrm{p} 1 \mathrm{~d}], \mathrm{H}[3 \mathrm{~s} 1 \mathrm{p}]$. The phenyl substituents in $\mathrm{Cu}(\mathrm{TPC})$

(51) Ahlrichs, R.; Bär, M.; Häser, M.; Horn, H.; Kölmel, C. Chem. Phys. Lett. 1989, 162, 165.

(52) Frisch, M. J. et al. Gaussian 03, Revision C.02, Gaussian, Inc., Wallingford, CT, 2004.

(53) Schäfer, A.; Huber, C.; Ahlrichs, R. J. Chem. Phys. 1994, 100, 58295835 .

(54) Karlström, G.; Lindh, R.; Malmqvist, P.-Å.; Roos, B. O.; Ryde, U.; Veryazov, V.; Widmark, P.-O.; Cossi, M.; Schimmelpfennig, B.; Neogrady, P.; Seijo, L. Computational Material Science 2003, 28, 222.

(55) Aquilante, F.; De Vico, L.; Ferré, N.; Ghigo, G.; Malmqvist, P.-Å.; Neogrády, P.; Pedersen, T. B.; Pitonák, M.; Reiher, M.; Roos, B. O.; Serrano-Andrés, L.; Veryazov, M. U. V.; Lindh, R. J. Comput. Chem. 2010, 31, 224-247.

(56) Pierloot, K.; Vancoillie, S. J. Chem. Phys. 2006, 125, 124303

(57) Pierloot, K.; Vancoillie, S. J. Chem. Phys. 2008, 128, 034104

(58) Roos, B. O.; Lindh, R.; Malmqvist, P.-A.; Veryazov, V.; Widmark, P.-O. J. Phys. Chem. A 2001, 109, 6575-6579. were described with smaller ANO-s basis sets, ${ }^{59}$ contracted to [3s 2 p] for $\mathrm{C}$ and [2s] for $\mathrm{H}$. In all calculations, advantageous use (in terms of computational times and disk storage needs) was made of Cholesky decomposition of the electron repulsion integral matrix ${ }^{60}$ (with a threshold of $\delta=10^{-6} \mathrm{au}$ ). Scalar relativistic effects were included using a standard secondorder Douglas-Kroll-Hess (DKH) Hamiltonian. ${ }^{61-64}$

The choice of the active orbitals for the CASSCF calculations is made according to the standard rules for transition metal compounds. ${ }^{65-67}$ Important correlation effects involving the $\mathrm{Cu} 3 \mathrm{~d}$ electrons are described by including in the active space 10 electrons in 11 molecular orbitals (10in11): five (predominantly) copper $3 \mathrm{~d}$ character, a second $\mathrm{d}$ shell to describe the so-called "double-shell" effect, ${ }^{65,66,68}$ and the bonding orbital involved in covalent $\sigma$ interaction between $\mathrm{Cu} 3 \mathrm{~d}$ and the corrolate nitrogen lone pairs. In order to allow transitions out of the corrole $\pi$ system leading to a $\mathrm{Cu}^{\mathrm{II}}$ state, the two highest $\pi$ orbitals of the corrole, as well as their correlating $\pi^{*}$ orbitals were included in the active space of the planar $\left(C_{2 v}\right)$ structures, thus giving an active space of 14 electrons in 15 molecular orbitals (14in15). On the basis of the CASPT2 relative energies found for the $C_{2 v}$ structures, only two corrole $\left(\pi, \pi^{*}\right)$ orbitals of $b$ symmetry were kept in the active space for the $C_{2}$ structures involved in the saddling distortion path, thus reducing the active space to 12 electrons in 13 orbitals (12in13). Single-point calculations on the $C_{2 v}$ structures and the $C_{2}$ structural minima were performed with an active space that was further extended to a total of 34 orbitals containing 36 electrons (36in34), that is, the basic (10in11) space augmented with the full set of 23 corrole $\pi$ orbitals, containing 26 electrons. CASSCF calculations with such a large active space are computationally unfeasible. Therefore, RASSCF calculations were instead performed. Hereto, the active space was further subdivided in three subspaces RAS $(1-3)$. The RAS2 space (playing the same role as the active space of a CASSCF calculation) was kept limited to either two or three orbitals. For the low-spin $\mathrm{Cu}^{\text {III }}$ state, only the empty $\mathrm{Cu} 3 \mathrm{~d}_{x^{2}-y^{2}}$ and its bonding $\mathrm{N}$ p $\sigma$ counterpart are included $\rightarrow(2 \mathrm{in} 2)$, while for each of the open-shell $\mathrm{Cu}^{\mathrm{II}}-\pi$ cation radical states, the appropriate (depopulated) corrolate $\pi$ orbital is also included $\rightarrow(4 \mathrm{in} 3)$. All other $\mathrm{Cu} 3 \mathrm{~d}$ and corrolate $\pi$ orbitals are contained in RAS1, while the $\mathrm{Cu}$ $4 \mathrm{~d}$ and corrolate $\pi^{*}$ orbitals are in RAS3. The RASSCF wave function is constructed by allowing up to double excitations from RAS1 to RAS3 (combined with all possible electron distributions in RAS2).

In all CASPT2/RASPT2 calculations, the core electrons, that is, from $(\mathrm{C}, \mathrm{N}, \mathrm{O}) 1 \mathrm{~s}$ and $\mathrm{Fe} 1 \mathrm{~s}-2 \mathrm{p}$, were kept frozen. To avoid weak intruder states as well as to provide a balanced description of open and closed shells, all CASPT2 calculations

(59) Pierloot, K.; Dumez, B.; Widmark, P.-O.; Roos, B. O. Theor. Chim. Acta 1995, 90, 87.

(60) Aquilante, F.; Malmqvist, P.-A.; Pedersen, T. B.; Ghosh, A.; Roos, B. O. J. Chem. Theor. Comput. 2007, 4, 694-702.

(61) Douglas, N.; Kroll, N. M. Ann. Phys. (N.Y.) 1974, 82, 89.

(62) Hess, B. Phys. Rev. A 1986, 33, 3742.

(63) Roos, B. O.; Malmqvist, P.-A. Phys. Chem. Chem. Phys. 2004, 6, 2919-2927.

(64) Reiher, M.; Wolf, A. J. Chem. Phys. 2004, 121, 10945-10956.

(65) Roos, B. O.; Andersson, K.; Fülscher, M. P.; Malmqvist, P.-Å.; Serrano-Andrés, L.; Pierloot, K.; Merchán, M. Multicongurational Perturbation Theory: Applications in 35 Electronic Spectroscopy. In Advances in Chemical Physics: New Methods in Computational Quantum Mechanics; Prigogine, I., Rice, S. A., Eds.; John Wiley \& Sons: New York, 1996; Vol. XCIII; pp 219-332.

(66) Pierloot, K. Nondynamic Correlation Effects in Transition Metal Coordination Compounds. In Computational Organometallic Chemistry; Cundari, T. R., Ed.; Marcel Dekker, Inc.: New York, 2001; pp 123-158. (67) Pierloot, K. Mol. Phys. 2003, 101, 2083-2094.

(68) Andersson, K.; Roos, B. O. Chem. Phys. Lett. 1992, 191, 507. 
Table 1. Structures and Relative Energies of the $C_{2 v}$ Structures

\begin{tabular}{|c|c|c|c|c|c|c|c|c|c|c|}
\hline & \multicolumn{5}{|c|}{$\mathrm{Cu}(\mathrm{C})$} & \multicolumn{5}{|c|}{$\mathrm{Cu}(\mathrm{TPC})$} \\
\hline & ${ }^{1} \mathrm{~A}_{1}\left[\mathrm{Cu}^{\mathrm{III}}\right]$ & ${ }^{1} \mathrm{~A}_{2}\left[\mathrm{Cu}^{\mathrm{II}}\right]^{a}$ & ${ }^{3} \mathrm{~A}_{2}\left[\mathrm{Cu}^{\mathrm{II}}\right]$ & ${ }^{1} \mathrm{~B}_{1}\left[\mathrm{Cu}^{\mathrm{II}}\right]^{a}$ & ${ }^{3} \mathrm{~B}_{1}\left[\mathrm{Cu}^{\mathrm{II}}\right]$ & ${ }^{1} \mathrm{~A}_{1}\left[\mathrm{Cu}^{\mathrm{III}}\right]$ & ${ }^{1} \mathrm{~A}_{2}\left[\mathrm{Cu}^{\mathrm{II}}\right]^{a}$ & ${ }^{3} \mathrm{~A}_{2}\left[\mathrm{Cu}^{\mathrm{II}}\right]$ & ${ }^{1} \mathrm{~B}_{1}\left[\mathrm{Cu}^{\mathrm{II}}\right]^{a}$ & ${ }^{3} \mathrm{~B}_{1}\left[\mathrm{Cu}^{\mathrm{II}}\right]$ \\
\hline \multicolumn{11}{|c|}{ BP86 } \\
\hline$R(\mathrm{Cu}-\mathrm{N})(\AA)$ & 1.879 & 1.925 & 1.925 & 1.916 & 1.916 & 1.876 & 1.923 & 1.923 & 1.913 & 1.913 \\
\hline$\Delta E(\mathrm{kcal} / \mathrm{mol})$ & 0.0 & 4.5 & 4.0 & 8.8 & 8.4 & 0.0 & 3.9 & 3.4 & 9.2 & 8.8 \\
\hline \multicolumn{11}{|c|}{ OLYP } \\
\hline$R(\mathrm{Cu}-\mathrm{N})(\AA)$ & 1.884 & 1.930 & 1.930 & 1.921 & 1.921 & 1.882 & 1.928 & 1.928 & 1.918 & 1.918 \\
\hline$\Delta E(\mathrm{kcal} / \mathrm{mol})$ & 0.0 & 2.2 & 1.5 & 6.8 & 6.4 & 0.0 & 1.5 & 0.8 & 7.0 & 6.5 \\
\hline \multicolumn{11}{|c|}{ B3LYP } \\
\hline$R(\mathrm{Cu}-\mathrm{N})(\AA)$ & 1.872 & 1.925 & 1.925 & 1.916 & 1.916 & 1.869 & 1.923 & 1.923 & 1.913 & 1.913 \\
\hline$\Delta E(\mathrm{kcal} / \mathrm{mol})$ & 7.4 & 0.6 & 0.0 & 5.2 & 5.1 & 8.0 & 0.6 & 0.0 & 6.4 & 6.3 \\
\hline \multicolumn{11}{|c|}{ PBE0 } \\
\hline$R(\mathrm{Cu}-\mathrm{N})(\AA)$ & 1.858 & 1.914 & 1.914 & 1.904 & 1.904 & 1.855 & 1.911 & 1.911 & 1.901 & 1.901 \\
\hline$\Delta E(\mathrm{kcal} / \mathrm{mol})$ & 8.7 & 0.6 & 0.0 & 5.6 & 5.5 & 9.3 & 0.6 & 0.0 & 6.9 & 6.8 \\
\hline \multicolumn{11}{|c|}{$\mathrm{CASPT}^{b}$} \\
\hline$\Delta E(\mathrm{kcal} / \mathrm{mol})$ & 0.0 & 8.0 & 8.1 & 20.2 & 20.7 & 0.0 & 6.8 & 7.0 & 21.4 & 21.8 \\
\hline \multicolumn{11}{|c|}{$\mathrm{RASPT}^{c}$} \\
\hline$\Delta E(\mathrm{kcal} / \mathrm{mol})$ & 0.0 & 7.4 & 6.6 & 14.7 & 14.5 & 0.0 & 6.5 & 5.7 & 14.2 & 13.9 \\
\hline
\end{tabular}

${ }^{a}$ Pure singlet in CASPT2/RASPT2; mixture of singlet and triplet in DFT. ${ }^{b}$ Obtained from single-point CASPT2 calculations at the PBE0 structures; active space (14in15). ${ }^{c}$ Obtained from single-point RASPT2 calculations at the PBE0 structures; active space (36in34).

were performed using the standard IPEA Hamiltonian with an imaginary level shift of 0.1 au. ${ }^{69,70}$

\section{Results and Discussion}

3.1. The Planar Structures. 3.1.1. DFT Results. Let us first focus on the planar, $C_{2 v}$ structures. Both molecules $\mathrm{Cu}(\mathrm{C})$ and $\mathrm{Cu}(\mathrm{TPC})$ are placed in the $x y$-plane, with the $C_{2}$ axis bisecting the $x$-and $y$-axes. This means that in the lowest $\mathrm{Cu}^{\text {III }}$ state, closed-shell $\mathrm{d}^{8}{ }^{1} \mathrm{~A}_{1}$, the empty copper $3 \mathrm{~d}$ type orbital is of $b_{2}$ symmetry and corresponds to $3 \mathrm{~d}_{x^{2}-y^{2}}$. Even though denoted as $b_{2}\left(\mathrm{~d}_{x^{2}-y^{2}}\right)$, this orbital in fact contains an important corrole $\sigma$ contribution, resulting from a strongly covalent $\sigma$-interaction between $\mathrm{Cu} 3 \mathrm{~d}_{\mathrm{x}^{2}-y^{2}}$ and the corrolate $\mathrm{N}$ lone pairs (see further, Figure 4). ${ }^{71} \mathrm{Cu}^{\mathrm{II}} \pi$-cation radical states may be obtained by moving an electron from either one of the two HOMO corrolate $\pi$ orbitals, of $b_{1}$ or $a_{2}$ symmetry, into the $b_{2}\left(d_{x^{2}-y^{2}}\right)$ orbital. This gives rise to four states ${ }^{3} \mathrm{~A}_{2},{ }^{1} \mathrm{~A}_{2}$ (configuration $b_{1}{ }^{1} b_{2}{ }^{1}$ ) and ${ }^{3} \mathrm{~B}_{1},{ }^{1} \mathrm{~B}_{1}$ (configuration $a_{2}{ }^{1} b_{2}{ }^{1}$ ). The open-shell singlets are essentially two-determinantal, and therefore they cannot be obtained from DFT. Instead, what is calculated when supplying the DFT code with, for example, the occupation $b_{1}{ }^{\uparrow} b_{2}{ }^{\downarrow}$ or $b_{1}{ }^{\downarrow} b_{2}{ }^{\uparrow}$ is a broken-spin (BS) state, containing an equal mixture of singlet and triplet character. This is also evidenced by the value of $\left\langle S^{2}\right\rangle$ obtained for these BS states, all very close to 1.0. The relative energies of the $\mathrm{Cu}^{\text {III }}{ }^{1} \mathrm{~A}_{1}$ state and the four $\mathrm{Cu}{ }^{\text {II }}$ states obtained from either DFT or CASPT2 are shown in Table 1. The table also gives the average $\mathrm{Cu}-\mathrm{N}$ distance

(69) Forsberg, N.; Malmqvist, P.-̊․ Chem. Phys. Lett. 1997, 274, 196.

(70) Ghigo, G.; Roos, B. O.; Malmqvist, P.-A. Chem. Phys. Lett. 2004, $396,142-149$.

(71) Strong covalency between the metal d orbitals and the nitrogen lone pairs in metal corroles has been observed already at several occasions, and has been held responsible for the stabilization of high metal oxidation states by corroles. $8,9,12,14,16$ obtained from the geometry optimizations within $C_{2 v}$ symmetry. As expected, these distances are systematically smaller for the $\mathrm{Cu}^{\mathrm{III}}$ than for the four $\mathrm{Cu}^{\mathrm{II}}$ states, although the differences are limited to $0.05 \AA$ or less. Also note that BP86 and B3LYP give very similar $\mathrm{Cu}-\mathrm{N}$ distances, while the distances obtained from PBE0 are somewhat $(0.01-0.02 \AA)$ shorter. All distances are systematically shorter by $0.003 \AA$ for $\mathrm{Cu}(\mathrm{TPC})$ than for $\mathrm{Cu}(\mathrm{C})$.

A first glimpse at the relative energies obtained from DFT already reveals the primary difference in the description of copper corroles between either the pure functionals BP86, OLYP, and the hybrid functionals B3LYP and PBE0. Using pure functionals, both $\mathrm{Cu}(\mathrm{C})$ and $\mathrm{Cu}(\mathrm{TPC})$ are found to have a $\mathrm{Cu}^{\mathrm{III}}$ diamagnetic ${ }^{1} \mathrm{~A}_{1}$ ground state. In contrast, B3LYP and PBE0 predict a $\mathrm{Cu}^{\mathrm{II}}$ diradical, with a single electron in the $b_{2}\left(\mathrm{~d}_{x^{2}-y^{2}}\right)$ orbital coupled ferromagnetically to a $b_{1}$ corrolate $\pi$ radical, this giving rise to $\mathrm{a}^{3} \mathrm{~A}_{2}$ ground state. It should be noted that the difference in ground state between both functional types is not the consequence of subtle shifts in the relative position of both involved states. The largest difference in the ${ }^{3} \mathrm{~A}_{2}-{ }^{1} \mathrm{~A}_{1}$ relative energy is found between the hybrid functional PBE0 and the pure functional BP86, and amounts to as much as $13 \mathrm{kcal} / \mathrm{mol}$ for both molecules. All four functionals essentially agree on the relative energy of the four $\mathrm{Cu}^{\mathrm{II}}$ diradical states. The two $b_{1}$ radical states are predicted at the lowest energy, with the $a_{2}$ radical states higher by $4.5-5.5 \mathrm{kcal} / \mathrm{mol}$ for $\mathrm{Cu}(\mathrm{C})$ and by $5.5-6.5 \mathrm{kcal} / \mathrm{mol}$ for $\mathrm{Cu}(\mathrm{TPC})$. In both cases, the corrole radical spin and the spin of the $\mathrm{Cu}^{\mathrm{II}}$ ion are coupled in a ferromagnetic fashion, in line with the strict orthogonality of the magnetic orbitals involved. ${ }^{72,73}$

(72) Chaudhuri, P.; Verani, C. N.; Bill, E.; Bothe, E.; Weyhermüller, T.; Wieghardt, K. J. Am. Chem. Soc. 2001, 123, 2213-2223.

(73) Ray, K.; Weyhermüller, T.; Neese, F.; Wieghardt, K. Inorg. Chem. $\mathbf{2 0 0 5}, 44,5345-5360$. 
Table 2. Relative Energy ( $\mathrm{kcal} / \mathrm{mol})$ of the Closed-Shell Singlet State ${ }^{1} \mathrm{~A}_{1}\left[\mathrm{Cu}^{\mathrm{III}}\right]$ and the Triplet States ${ }^{3} \mathrm{~A}_{2}\left[\mathrm{Cu}^{\mathrm{II}}\right]$ and ${ }^{3} \mathrm{~B}_{1}\left[\mathrm{Cu}^{\mathrm{II}}\right]$ of $\mathrm{Cu}(\mathrm{C})^{a}$, as a Function of the Amount of Hartree-Fock Exchange in the B3LYP Functional

\begin{tabular}{lccc}
\hline \multicolumn{1}{c}{$\operatorname{method}^{b}$} & ${ }^{1} \mathrm{~A}_{1}\left[\mathrm{Cu}^{\mathrm{III}}\right]$ & ${ }^{3} \mathrm{~A}_{2}\left[\mathrm{Cu}^{\mathrm{II}}\right]$ & ${ }^{3} \mathrm{~B}_{1}\left[\mathrm{Cu}^{\mathrm{II}}\right]$ \\
\hline S-VWN & 0.0 & 12.3 & 16.8 \\
B3LYP(0) & 0.0 & 5.2 & 9.5 \\
B3LYP(2) & 0.0 & 4.1 & 8.5 \\
B3LYP(5) & 0.0 & 2.4 & 7.0 \\
B3LYP(10) & 0.7 & 0.0 & 4.8 \\
B3LYP(15) & 3.9 & 0.0 & 5.0 \\
B3LYP(20) & 7.4 & 0.0 & 5.1 \\
B3LYP(25) & 11.1 & 0.0 & 5.1 \\
B3LYP(50) & 32.6 & 0.0 & 4.9 \\
B3LYP(100) & 88.9 & 0.9 & 0.0 \\
HF & 83.9 & 0.0 & 0.3
\end{tabular}

${ }^{a}$ Single-point calculations performed at the respective B3LYP structures. ${ }^{b} \mathrm{~B} 3 \mathrm{LYP}(\mathrm{n})$ standing for a B3LYP alternative containing $\mathrm{n} \% \mathrm{HF}$ exchange. B3LYP(20) corresponds to regular B3LYP; B3LYP(15) corresponds to $\mathrm{B} 3 \mathrm{LYP} *{ }^{74}$

The different behavior of the pure GGA functionals on the one and the hybrid functionals on the other hand is of course related to the presence in the latter functionals of a distinct amount of Hartree-Fock exchange, that is, $20 \%$ in B3LYP and $25 \%$ in PBE0. This is illustrated by Table 2 , showing the results of a series of test calculations on $\mathrm{Cu}(\mathrm{C})$, starting from the B3LYP functional (i.e., with the same contributions of the Becke exchange and the VWN/ LYP correlation functionals) but systematically varying the contribution of HF exchange (at the expense of Slater exchange) between $0 \%$ and $100 \%$. Using the HartreeFock method (results shown at the bottom of the table), the stability of both $\mathrm{Cu}^{\mathrm{II}}$ open-shell states ${ }^{3} \mathrm{~A}_{2},{ }^{3} \mathrm{~B}_{1}$ is obviously grossly overestimated, with the $\mathrm{Cu}^{\text {III }}{ }^{1} \mathrm{~A}_{1}$ state calculated as high as $84 \mathrm{kcal} / \mathrm{mol}$ above ${ }^{3} \mathrm{~A}_{2}$. This is also reflected in the B3LYP $(100)$ result, giving an even larger number $\left(88 \mathrm{kcal} / \mathrm{mol}\right.$ ) for the ${ }^{1} \mathrm{~A}_{1}-{ }^{3} \mathrm{~A}_{2}$ splitting. On the other hand, with local DFT (S-VWN in Table 2) $\mathrm{Cu}(\mathrm{C})$ is found to have a closed-shell ${ }^{1} \mathrm{~A}_{1} \mathrm{Cu}^{\mathrm{III}}$ ground state, more stable by $12.3 \mathrm{kcal} / \mathrm{mol}$ compared to the lowest triplet state ${ }^{3} \mathrm{~A}_{2}$. Again, this result is carried over into B3LYP(0). Because of the large difference found for the singlettriplet splittings between the HF and local DFT methods, the ${ }^{1} \mathrm{~A}_{1}$ state shows a steep energy increase as the amount of $\mathrm{HF}$ exchange is increased. As Table 2 indicates, at a HF exchange contribution between $5-10 \%$, the ground state of $\mathrm{Cu}(\mathrm{C})$ switches from $\mathrm{Cu}^{\mathrm{III}}$ closed-shell singlet to $\mathrm{Cu}^{\mathrm{II}}$ ${ }^{3} \mathrm{~A}_{2}$. The results in the rightmost column of this table also show that the relative energy of both triplet states ${ }^{3} \mathrm{~A}_{2}$ and ${ }^{3} \mathrm{~B}_{1}$ is much less dependent on the HF exchange contribution, at least for values ranging between $0-50 \%$, giving a constant ${ }^{3} \mathrm{~B}_{1}-{ }^{3} \mathrm{~A}_{2}$ splitting of around $5 \mathrm{kcal} / \mathrm{mol}$. On the other hand, both HF and B3LYP(100) predict these two triplet states to be close to degenerate.

The situation observed here is reminiscent of previous observations in a somewhat different context. In a series of DFT studies on the relative energetics of different ligand field states in ferrous and ferric compounds with

(74) Reiher, M.; Salomon, O.; Hess, B. A. Theor. Chem. Acc. 2001, 107, $48-55$.

(75) Radoń, M.; Pierloot, K. J. Phys. Chem. A 2008, 112, 11824-11832.

(76) Vancoillie, S.; Zhao, H.; Radoń, M.; Pierloot, K. J. Chem. Theory Comput. 2010, 6, 576-582.

(77) Radon, M.; Broclawik, E.; Pierloot, K. J. Phys. Chem. B 2010, 114, 1518-1528. both heme and non-heme architectures, we have found that also the results are critically dependent on the applied functional. ${ }^{56,57,75-77}$ In particular, it was found that traditional GGAs systematically overstabilize low-spin (strong-field) relative to high-spin (weak-field) states, while hybrid functionals perform better, but with the high spin state becoming more favored as the contribution of Hartree-Fock exchange is increased. These observations could be traced back to the inherent bias of HartreeFock toward high-spin states on the one hand, with on the other hand the local DFT approach underestimating Fermi correlation, thus overstabilizing low-spin states. Though becoming less severe, the latter fault is still systematically present in all classic GGAs ${ }^{78-80}$ As a matter of fact, DFT results obtained for the spin pairing energy in ferrous complexes were shown to be relatively indifferent to the type of correlation functional, while steeply increasing when introducing an increasing amount of Hartree-Fock exchange. ${ }^{79}$ An exception was found for the GGAfunctional OLYP. This functional was shown in several studies ${ }^{57,75-77,79,80}$ to describe correctly the spin-pairing energetics in ferrous and ferric compounds, giving results that are systematically closer to the "standard" hybrid B3LYP than to other pure functional results, in fact most frequently outperforming the former functional.

Returning to the present copper corrole results, most trends observed for the relative energies between the openshell $\mathrm{Cu}^{\mathrm{II}}$ and closed-shell $\mathrm{Cu}^{\mathrm{III}}$ states are obviously similar to the trends observed for the iron compounds. Also here we find a close correspondence between the results obtained with BP86 (Table 1) and B3LYP(0) (Table 2) for the two triplet states in $\mathrm{Cu}(\mathrm{C}): 4.0 \mathrm{kcal} / \mathrm{mol}$ versus $5.2 \mathrm{kcal} / \mathrm{mol}$ $\left({ }^{3} \mathrm{~A}_{2}\right)$ and $8.4 \mathrm{kcal} / \mathrm{mol}$ versus $9.5 \mathrm{kcal} / \mathrm{mol}\left({ }^{3} \mathrm{~B}_{1}\right)$. Furthermore, these results also conform to the first DFT (PW91) calculations from Ghosh's group ${ }^{7}$ on planar $\mathrm{Cu}(\mathrm{C})$, predicting the ${ }^{3} \mathrm{~A}_{2}$ and ${ }^{3} \mathrm{~B}_{1}$ state at respectively 3.7 and $8.2 \mathrm{kcal} / \mathrm{mol}$. This indicates that the relative stability of these states is much less dependent on the specific expression of the DFT functional than on the contribution of HF exchange. As to be expected, with $25 \% \mathrm{HF}$ exchange, $\mathrm{PBE} 0$ gives results that are closer to HF and B3LYP(100) than B3LYP. As concerns OLYP, we find that also here this functional gives results that are closer to B3LYP than the other GGAs. However, the shift toward the hybrid functionals is not large enough to change the character of the ground state from $\mathrm{Cu}^{\text {III }}{ }^{\mathrm{I}} \mathrm{A}_{1}$ to $\mathrm{Cu}^{\text {II } 3} \mathrm{~A}_{2}$.

3.1.2. Multiconfigurational ab Initio Results. Turning next to the multiconfigurational ab initio results in Table 1 , we find that both CASPT2 and RASPT2 predict a lowspin $\mathrm{Cu}^{\text {III }}$ ground state, with the lowest $\mathrm{Cu}^{\text {II }}$ state corresponding to a $b_{1}$ radical. Both methods thus qualitatively agree with BP86, although one can see that the $\mathrm{Cu}^{\mathrm{II}}$ states are found at much higher energies with the traditional correlated methods than with DFT. This is true in particular for the $\mathrm{B}_{1}$ states, predicted about $12 \mathrm{kcal} / \mathrm{mol}$ higher in energy (relative to ${ }^{1} \mathrm{~A}_{1}\left[\mathrm{Cu}{ }^{I I I}\right]$ ) with CASPT2 than with BP86. This difference is reduced to $6 \mathrm{kcal} / \mathrm{mol}$ with RASPT2.

(78) Fouqueau, A.; Mer, S.; Casida, M. E.; Lawson Daku, L. M.; Hauser, A.; Mineva, T.; Neese, F. J. Chem. Phys. 2004, 120, 9473-9486.

(79) Ganzenmüller, G.; Berkaïne, N.; Fouqueau, A.; Casida, M. E.; Reiher, M. J. Chem. Phys. 2005, 122, 234321.

(80) Fouqueau, A.; Casida, M. E.; Lawson Daku, L. M.; Hauser, A.; Neese, F. J. Chem. Phys. 2005, 122, 044110. 

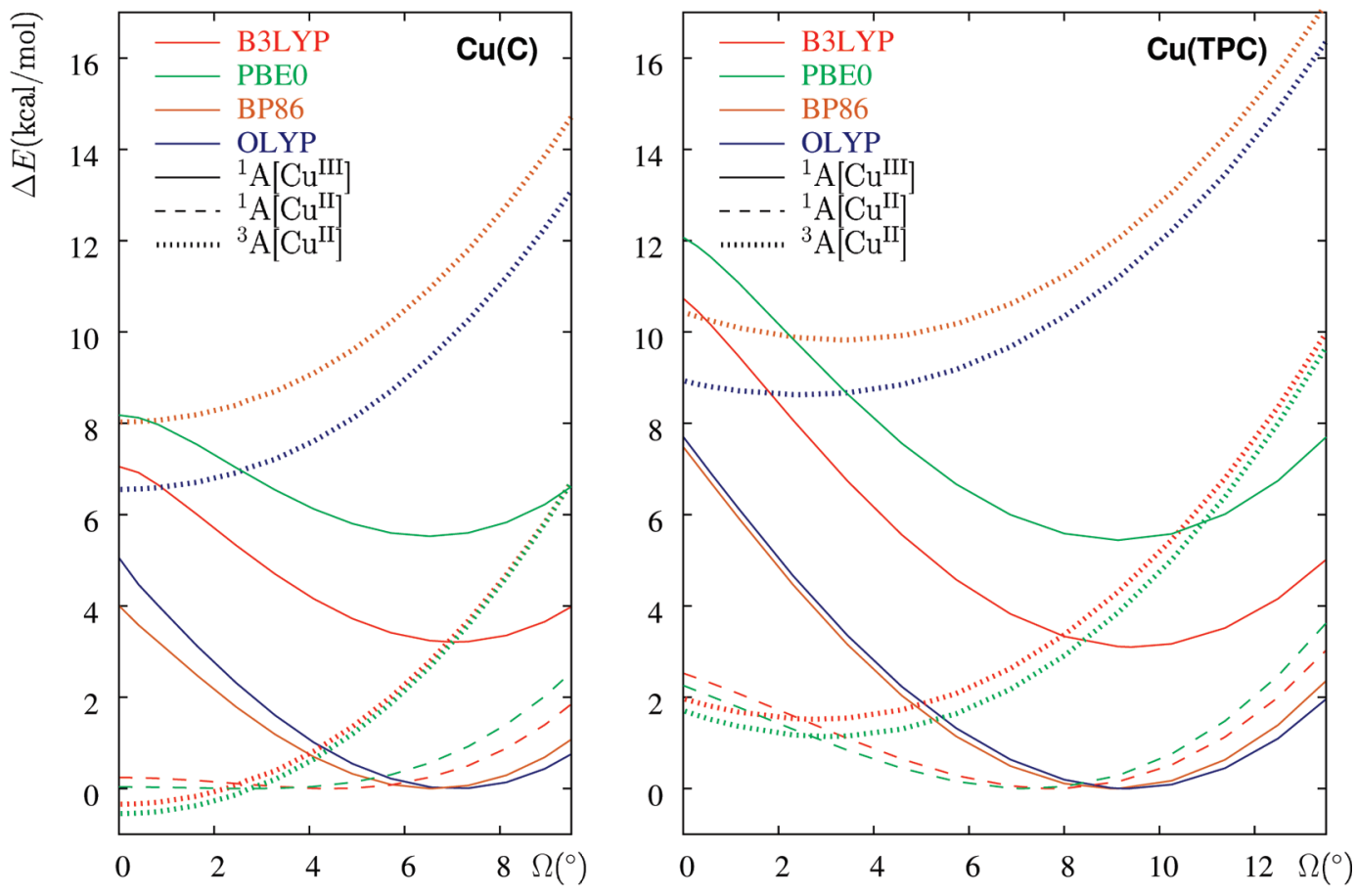

Figure 2. Energy profile along the out-of-plane angle $\Omega$, obtained with different DFT functionals.

The differences are smaller for the $\mathrm{A}_{2}$ states, with also here RASPT2 giving results that are (slightly) closer to BP86 than CASPT2. Another important difference between the CASPT2 and RASPT2 results is that with the former approach the exchange coupling in the biradical $\mathrm{Cu}^{\mathrm{II}}$ states is found to be antiferromagnetic, as opposed to the ferromagnetic coupling predicted by RASPT2 and DFT and a priori to be expected for the exchange coupling between two orthogonal magnetic orbitals. This fact, together with the overall closer correspondence with BP86, strongly suggests that the RASPT2 results in Table 1 are superior to CASPT2. This result should be related to the composition of the active space used to build the RASSCF reference wave function, containing the full set of corrole $\pi$ orbitals, instead of only the two HOMO $\pi$ orbitals $b_{1}, a_{2}$, and their correlating LUMO partners. As a concession to the considerable enlargement of the active space (with 19 orbitals), the excitation level is in the RASSCF calculations limited to up-to-doubles instead of full CI in CASSCF. This holds both for the copper $3 d-4 d$ excitations describing the $3 d$ double-shell effect and for the corrole $\pi-\pi^{*}$ excitations. In a previous RASPT2 study on $\mathrm{CuO}_{2}$ systems, we have already shown ${ }^{50}$ that the double-shell effect on one copper center may be quite accurately described by using only SDCI in the RASSCF reference wave function, providing RASPT2 results that are close to CASPT2. The present results indicate that compromising on the excitation level in the corrole $\pi$ shell in order to allow for a larger set of active orbitals may be quite a favorable operation in terms of the accuracy to be obtained from the perturbational treatment. It seems that an active space containing only the four HOMO-LUMO $\pi$ orbitals might in fact be too small to provide a balanced treatment between $\mathrm{Cu}^{\text {III }}$ and the different $\mathrm{Cu}^{\mathrm{II}}-\pi$ cation radical states as well as between the latter states among themselves.

3.2. The Saddling Distortion. 3.2.1. DFT Results. Next, we consider the saddling distortion path which allows the planar corrole structures to relax to their $C_{2}$ structural minima. The DFT energy profile along the out-of-plane angle $\Omega$ is shown in Figure 2. Structural data and relative energies of the different $C_{2}$ states are presented in Table 3 . Only states corresponding to ${ }^{1} \mathrm{~A}_{1}\left[\mathrm{Cu}^{\mathrm{III}}\right]$ and the lowest $\mathrm{Cu}^{\mathrm{I}}$ states ${ }^{3} \mathrm{~A}_{2},{ }_{1} \mathrm{~A}_{2}$ within $C_{2 v}$ are considered, as the ${ }^{3} \mathrm{~B}_{1},{ }^{3} \mathrm{~B}_{1}$ states are too high in energy to become a possible ground state candidate in the saddled structures. Upon symmetry lowering from $C_{2 v}$ to $C_{2}$, the $C_{2 v}$ representations $a_{1}$ and $a_{2}$ are reduced to $a, b_{1}$ and $b_{2}$ to $b$. At the orbital level, this means that mixing between the orbitals $b_{2}\left(\mathrm{~d}_{x^{2}-y^{2}}\right)$ and the corrole HOMO $b_{1}(\pi)$ orbital, orthogonal within $C_{2 v}$, becomes symmetry-allowed. At the state level, it means that the considered singlet states, closed-shell ${ }^{1} \mathrm{~A}_{1}$ and open-shell ${ }^{1} \mathrm{~A}_{2}$, both become ${ }^{1} \mathrm{~A}$, and are therefore allowed to mix. Moreover, under $C_{2}$ symmetry both states have the same number of electrons of each spin in either set of $a$ - or $b$-type orbitals and are thus formally indistinguishable. With PBE0 or B3LYP, the energy profile of the lowest $\mathrm{Cu}^{\mathrm{II}}$ diradical state in Figure 2 is obtained from a broken-spin DFT calculation, denoted as ${ }^{1} \mathrm{~A}\left[\mathrm{Cu}^{\mathrm{II}}\right]$ (although this state remains of course seriously spin-contaminated; see further). When applying instead the spin-restricted DFT formalism, the higher-lying closed-shell ${ }^{1} \mathrm{~A}$ solution is obtained. On the other hand, with the pure GGAs BP86 and OLYP, any spin-unrestricted calculation on the ${ }^{1} \mathrm{~A}$ state always results in pure singlet, closed-shell ${ }^{1} \mathrm{~A}$ ground state.

Considering first the results obtained with the pure functionals, we find (Figure 2) that both BP86 and OLYP predict a saddled closed-shell singlet ground state structure for both complexes. The degree of saddling, reflected by the out-of-plane angle $\Omega$, is similar for both functionals, but is larger for $\mathrm{Cu}$ (TPC), $\Omega=7.50-9.12^{\circ}$, than for $\mathrm{Cu}(\mathrm{C}), \Omega=5.47-5.84^{\circ}$. Consequently, the amount of energy gained from saddling is also larger for the substituted structure, $7.5-7.7 \mathrm{kcal} / \mathrm{mol}$, as compared to only $4.0-5.0 \mathrm{kcal} / \mathrm{mol}$ for $\mathrm{Cu}(\mathrm{C})$. The present OLYP structures are in line with recently reported structures obtained with 
Table 3. Structures and Relative Energies of the Lowest Singlet and Triplet States of $\mathrm{Cu}(\mathrm{C})$ and $\mathrm{Cu}(\mathrm{TPC})$

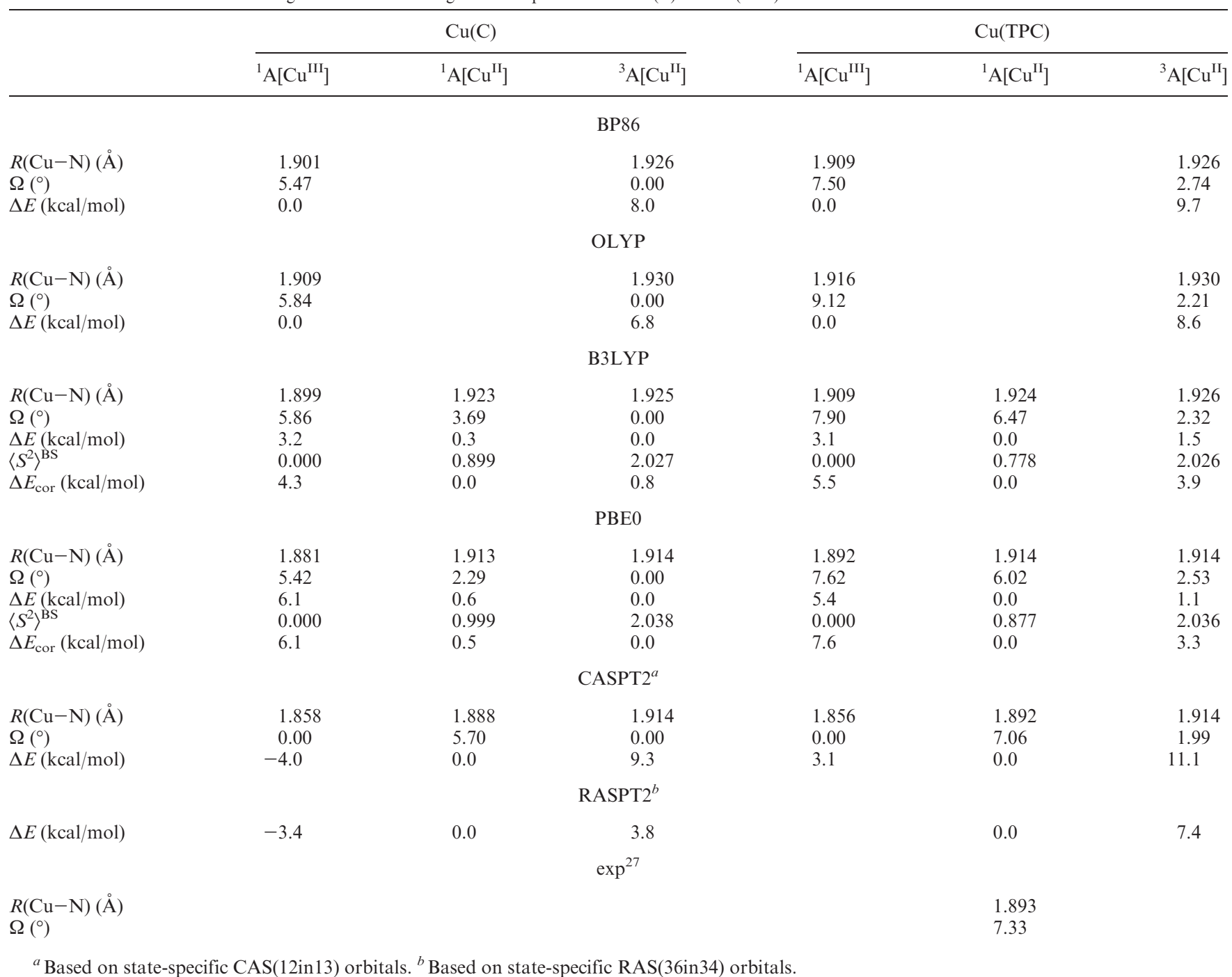

the same functional ${ }^{25}$ (Slater TZP basis sets), showing also a more profound saddling distortion for $\mathrm{Cu}(\mathrm{TPC})$ (and even more for substituted phenyl groups) than for unsubstituted $\mathrm{Cu}(\mathrm{C})$. From the Cartesian coordinates of the OLYP structures (provided in the Supporting Information of ref 25 ), an $\Omega$-angle of $4.78^{\circ}$ may be calculated for $\mathrm{Cu}(\mathrm{C})$ and $7.21^{\circ}$ for $\mathrm{Cu}(\mathrm{TPC})$, that is, slightly smaller than the present OLYP and BP86 values. The nonplanar distortion of copper corroles was ascribed by Alemayehu et al. ${ }^{25}$ to a "specific metal d-corrole $\pi$ orbital interaction", manifested by the composition of the HOMO $b$ orbital (OLYP), showing extensive mixing of copper $\mathrm{d}_{x^{2}-y^{2}}$ and corrolate $\pi$ character. These findings are confirmed by the present OLYP and BP86 results. As a matter of fact, significant $\mathrm{Cu} 3 \mathrm{~d}_{x^{2}-y^{2}}$ character is not only observed for the HOMO, but also for a number of lower-lying doubly occupied orbitals. Plots of all $b$-type orbitals (BP86) containing a significant contribution $(>5 \%)$ of $\mathrm{Cu} 3 \mathrm{~d}_{x^{2}-y^{2}}$ character are provided in the Supporting Information (Tables $\mathrm{S} 1-\mathrm{S} 4$ ). The resulting gross (Mulliken) population of $\mathrm{Cu} 3 \mathrm{~d}_{x^{2}-y^{2}}$ in the $C_{2}$ structures amounts to 1.48 electrons in $\mathrm{Cu}(\mathrm{C})$ and 1.50 electrons in $\mathrm{Cu}(\mathrm{TPC})$, thus giving both complexes substantial $\mathrm{Cu}^{\mathrm{II}}$ character, as was also reported by Alemayehu. ${ }^{25}$ How- ever, it should be noted that also in the planar structure considerable mixing of $\mathrm{Cu} 3 \mathrm{~d}_{x^{2}-y^{2}}$ character occurs in the doubly occupied $b_{2}$ (pure $\sigma$ ) orbitals, in particular in the HOMO. The resulting $\mathrm{Cu} 3 \mathrm{~d}_{x^{2}-y^{2}}$ gross population is in this case 1.40 electrons for both molecules. This indicates that mixing of corrole $\pi$ character due to saddling in fact hardly affects the effective metal oxidation state. Furthermore, we cannot go along with the conclusion put forward in ref 25 that the description provided by OLYP (or BP86) of the metal $\mathrm{d}$-corrole $\pi$ interaction in the saddled structures involves a noninnocent corrole ligand, and that this interaction should therefore rather be described as $\mathrm{Cu}^{\text {II }}$ corrolate $^{\cdot 2-}$. A noninnocent ligand is, by definition, a radical. ${ }^{72}$ As such, interaction between a transition metal and a noninnocent ligand inherently requires an openshell treatment, which can within DFT only be provided in a spin-unrestricted solution. In the closed-shell ${ }^{1} \mathrm{~A}$ solution obtained from BP86 or OLYP, both electrons involved in the metal $\mathrm{d}-$ corrole $\pi$ interaction are paired with antiparallel spin in a single HOMO. Consequently, they occupy the same regions of space in the molecule, and their interaction can by no means be described as diradical. The diradical character of the present copper corroles will be discussed further in Section 3.3. 
Obviously, a different picture is obtained with the hybrid functionals PBE0 and B3LYP. In Figure 2, the ${ }^{1} \mathrm{~A}$ ground state obtained with these two functionals correlates to the open-shell broken-spin ${ }^{1} \mathrm{~A}_{2}$ solution within $C_{2 v}$, containing two radical spins in the orthogonal $b_{1}(\pi)$ and $b_{2^{-}}$ $\left(\mathrm{d}_{x^{2}-y^{2}}\right)$ orbitals. The saddling distortion of the corrole ligand allows for $\sigma-\pi$ interaction between these orbitals, thus giving rise to antiferromagnetic exchange coupling between both spins, the strength of which increases as the saddling becomes stronger. Within the unrestricted treatment offered by DFT, increasing antiferromagnetic coupling is manifested by a decreasing value of $\left\langle S^{2}\right\rangle^{\mathrm{BS}}$ for the broken-spin state (as compared to the pure diradical value of 1.0), pointing to an increasing contribution of singlet closed-shell at the expense of diradical character (values of $\left\langle S^{2}\right\rangle^{\mathrm{BS}}$ are also given in Table 3 ). As can be seen from Figure 2 and Table 3, both hybrid functionals predict a larger degree of saddling for $\mathrm{Cu}(\mathrm{TPC})$ than for $\mathrm{Cu}(\mathrm{C})$, consistent with a larger energy gain and a smaller $\left\langle S^{2}\right\rangle^{\mathrm{BS}}$ value for the former structure. These effects are slightly larger with B3LYP than with PBE0. However, it is clear from Figure 2 that the saddling deformation is considerably more soft for the open-shell ${ }^{1} \mathrm{~A}(\mathrm{BS})$ ground state calculated with the hybrid functionals than for the closed-shell ${ }^{1} \mathrm{~A}$ ground state obtained from the pure GGAs. Also noteworthy is that the energy profile calculated for the alternative closed-shell ${ }^{1} \mathrm{~A}$ solution with B3LYP and PBE0 is in fact very similar to the BP86 and OLYP curves, even though these curves are shifted upward by almost $4 \mathrm{kcal} / \mathrm{mol}$ with B3LYP and by around $6 \mathrm{kcal} / \mathrm{mol}$ with PBE0. Similarly shaped curves are also obtained with all four functionals for the lowest triplet state ${ }^{3} \mathrm{~A}$. As Figure 2 shows, the triplet state of $\mathrm{Cu}(\mathrm{C})$ is found to be planar, whereas for $\mathrm{Cu}$ (TPC) a slight distortion is calculated, with $\Omega$ between $1-3$ deg and an energy gain smaller than $1 \mathrm{kcal} / \mathrm{mol}$. This is a further indication that the driving force of the saddling distortion in the singlet states is primarily of electronic nature rather than steric. However, we have shown here that different functional types provide a different description of this electronic driving force. With pure functionals, it is attributed to an additional dative two-electron donation from the corrole $b$ type $\pi$-orbital into $b\left(\mathrm{~d}_{x^{2}-y^{2}}\right)$, while with hybrid functionals the driving force is the strengthening of the antiferromagnetic exchange coupling of an electron in the singly occupied corrole $b$ type $\pi$-orbital with the unpaired copper $3 \mathrm{~d}$ electron in the $b\left(\mathrm{~d}_{x^{2}-y^{2}}\right)$ orbital.

Table 3 also includes the adiabatic energy difference $\Delta E$ between the lowest ${ }^{3} \mathrm{~A}$ and ${ }^{1} \mathrm{~A}$ states. NMR spectra of copper corroles have since long been shown to exhibit a strong temperature dependence, ascribed to an equilibrium between a diamagnetic $\mathrm{d}^{8} \mathrm{Cu}^{\text {III }}$ corrole and a paramagnetic $\mathrm{Cu}^{\mathrm{II}}$ corrole $\pi$-cation radical of higher energy. Although the triplet state has been reported as being thermally accessible in corroles with various substituents, a precise value of $\Delta H=24.1 \pm 2.5 \mathrm{~kJ} / \mathrm{mol}$ or $5.8 \mathrm{kcal} / \mathrm{mol}$ has only recently been provided for $\beta$-octaethyl-5,15-diphenylcorrole. ${ }^{22}$ In this work, only data for the relative electronic energy $\Delta E$ between the lowest triplet and singlet states are presented. In a separate project on a series of copper

(81) Pierloot, K.; Vancoillie, S.; Ngo, T. H.; Maes, W.; Dehaen, W.; Meervelt, L. V.; Robeyns, K., in preparation. corroles with various substituents, we have also studied zero-point energy corrections and finite-temperature effects to obtain the corresponding $\Delta H$ and $\Delta G$ values. ${ }^{81}$ The effect of thermodynamic corrections on the triplet-singlet splittings is most important when considering the pure DFT results (since here they refer to the energy difference between an open- and a closed-shell), stabilizing the triplet by about $0.5-1.4 \mathrm{kcal} / \mathrm{mol}$. When subtracting this number from the $\Delta E$ values obtained from BP86 and OLYP, the resulting energy differences are in reasonable agreement with the experimental $\Delta H$ value of $5.8 \mathrm{kcal} / \mathrm{mol}$. The $\Delta E$ values obtained from B3LYP and PBE0 are much smaller. In fact, for $\mathrm{Cu}(\mathrm{C})$ the planar triplet state is found at the lowest energy with both functionals. For $\mathrm{Cu}$ (TPC) antiferromagnetic coupling is predicted, with an energy difference of $1.1-1.5 \mathrm{kcal} / \mathrm{mol}$ between the ${ }^{3} \mathrm{~A}$ and the ${ }^{1} \mathrm{~A}(\mathrm{BS})$ state. A more realistic value of $\Delta E$ may be obtained after applying a correcting for spin contamination to the energy of the BS state. This correction is obtained as

$$
\Delta E_{J}=x J
$$

where $x$ is a measure of spin contamination in the BS state $\left(\left\langle S^{2}\right\rangle_{\text {EXACT }}^{\text {BS }}\right.$ representing the $\left\langle S^{2}\right\rangle$ value of the corresponding pure spin state; $\left\langle S^{2}\right\rangle_{\text {EXACT }}^{\mathrm{BS}}=0$ in the case considered here):

$$
x=\left\langle S^{2}\right\rangle^{\mathrm{BS}}-\left\langle S^{2}\right\rangle_{\mathrm{EXACT}}^{\mathrm{BS}}
$$

and $J$ is the effective exchange coupling constant of the Heisenberg-Dirac-Van Vleck Hamiltonian: ${ }^{82-84}$

$$
J=\frac{E^{\mathrm{BS}}-E^{\mathrm{HS}}}{\left\langle S^{2}\right\rangle^{\mathrm{HS}}-\left\langle S^{2}\right\rangle^{\mathrm{BS}}}
$$

the HS state being obtained from a separate energy calculation at the equilibrium geometry of the BS state.

The corrected values are also given in Table 3. As one can see $\mathrm{Cu}(\mathrm{C})$ is still ferromagnetic with PBE0 but becomes antiferromagnetically coupled with B3LYP. For $\mathrm{Cu}(\mathrm{TPC})$, the correction is significantly larger, thus giving rise to a triplet-singlet splitting of 3.3-3.9 kcal $/ \mathrm{mol}$. Thermodynamic energy corrections are less important in this case, since now they refer to the energy difference between two open-shell states. ${ }^{81}$ The adiabatic triplet-singlet splittings with the hybrid functionals for $\mathrm{Cu}$ (TPC) are smaller by $5.0-6.3 \mathrm{kcal} / \mathrm{mol}$ for $\mathrm{Cu}(\mathrm{C})$ and by $2.0-2.5 \mathrm{kcal} / \mathrm{mol}$ for $\mathrm{Cu}$ (TPC) than the experimental $\Delta H$ value of $5.8 \mathrm{kcal} / \mathrm{mol}$ for $\beta$-octaethyl-5,15-diphenylcorrole.

3.2.2. Multiconfigurational ab Initio Results. Plots of the relative CASPT 2 energy of the two lowest ${ }^{1} \mathrm{~A}$ and the ${ }^{3} \mathrm{~A}$ states in both corroles as a function of the saddling angle $\Omega$ are given in Figure 3. Calculation of the saddling distortion path with CASPT2 is far from straightforward. First, since full geometry optimizations at this correlated level are computationally far too expensive, we have to settle for single-point calculations using structures obtained from DFT. For this the structures obtained with

(82) Rodriguez, J. H.; Wheeler, D. E.; McCusker, J. K. J. Am. Chem. Soc. 1998, 120, 12051-12068.

(83) Rodriguez, J. H.; McCusker, J. K. J. Chem. Phys. 2002, 116, 6253 6270

(84) Soda, T.; Kitagawa, Y.; Onishi, T.; Takano, Y.; Shigeta, Y.; Nagao, H.; Yoshioka, Y.; Yamaguchi, K. Chem. Phys. Lett. 2000, 319, 223-230. 

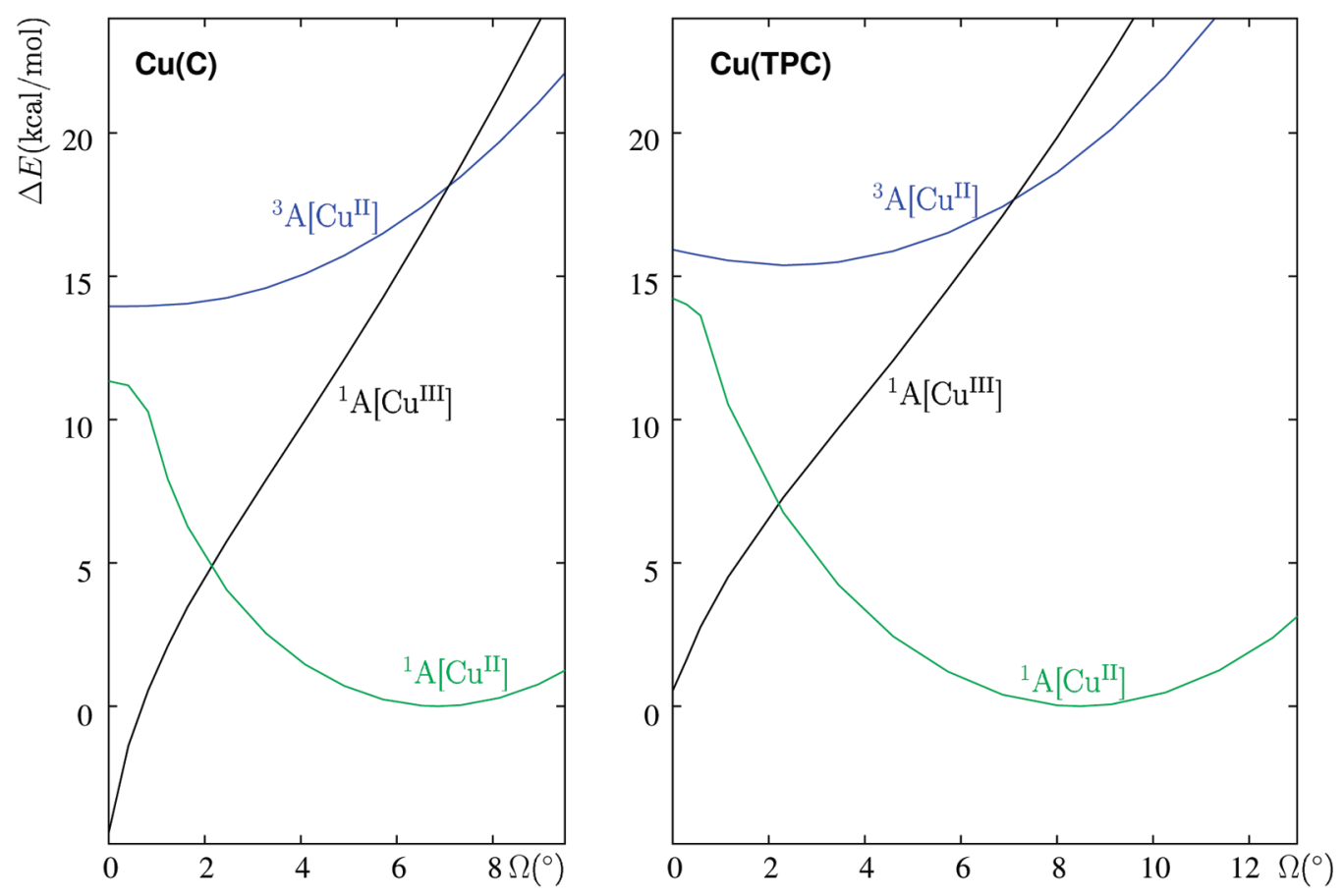

Figure 3. Energy profile along the out-of-plane angle $\Omega$, obtained from CASPT2, active space (12in13). For the two ${ }^{1} \mathrm{~A}$ states, state-average CASSCF orbitals were used.

the PBE0 functional were used. This may not seem the obvious choice at first, given the strongly different results obtained from PBE0 and CASPT2 for the relative energies of the low-lying states in the $C_{2 v}$ structures (Table 1). However, test calculations performed using structures obtained with different functionals indicate that the PBE0 structures systematically yield the lowest CASPT2 energies. Somewhat remarkably, from these tests we also found that, with the exception of the smallest saddling angles $\Omega$, a significantly lower energy was obtained from CASPT2 for the open-shell ${ }^{1} \mathrm{~A}$ state when applying this method to the structures obtained from the restricted (PBE0) DFT (RDFT) treatment rather than to the open-shell UDFT structures. Therefore, in Figure 3, only for the smallest values of $\Omega\left(<1.0^{\circ}\right.$ for $\mathrm{Cu}(\mathrm{C})$ and $<0.5^{\circ}$ for $\left.\mathrm{Cu}(\mathrm{TPC})\right)$ both ${ }^{1} \mathrm{~A}$ states were obtained using a different PBE0 structure (RDFT for ${ }^{1} \mathrm{~A}\left[\mathrm{Cu}^{\mathrm{III}}\right]$ and UDFT for ${ }^{1} \mathrm{~A}\left[\mathrm{Cu}^{\mathrm{II}}\right]$ ). For larger $\Omega$-angles, the CASPT2 energies of both states were obtained using the same (RDFT) PBE0 structure.

A second complication when performing CASPT2 concerns the CASSCF reference wave functions for the $C_{2}{ }^{1} \mathrm{~A}$ states. Even though the HF tendency to overstabilize the open-shell with respect to the closed-shell singlet (Table 2) is reduced in CASSCF, it is still manifestly present. For example, in the $C_{2 v}$ structures of $\mathrm{Cu}(\mathrm{C})$ the open-shell ${ }^{1} \mathrm{~A}_{2}$ state is calculated $13 \mathrm{kcal} / \mathrm{mol}$ below the ${ }^{1} \mathrm{~A}_{1}$ ground state at the CASSCF level, while only after the perturbation treatment their ordering is reversed. This also means that within $C_{2}$ symmetry the closed-shell ${ }^{1} \mathrm{~A}$ wave function is found as the second root in the CASSCF calculations. Because of the occurrence of root flipping, it is impossible to obtain state-specific CASSCF orbitals for this state. For this reason, the CASPT 2 calculations of both ${ }^{1} \mathrm{~A}$ states in Figure 3 were based on one set of state-average CASSCF orbitals. This has a distinct influence on the CASPT2 energies of both states involved. The effect is clearly noticeable when comparing to the ${ }^{3} \mathrm{~A}$ state in Figure 3 , the CASPT2 treatment of this state being based on its own state-specific orbitals. At $\Omega=0$, the ${ }^{3} \mathrm{~A}\left[\mathrm{Cu}^{\mathrm{II}}\right]$ state should become nearly degenerate with the open-shell ${ }^{1} \mathrm{~A}\left[\mathrm{Cu}^{\mathrm{II}}\right]$ state (since they correspond to ${ }^{3} \mathrm{~A}_{2}$ and ${ }^{1} \mathrm{~A}_{2}$ in $C_{2 v}$ ). However, one can see that, because it is calculated with average orbitals, the ${ }^{1} \mathrm{~A}\left[\mathrm{Cu}^{\mathrm{II}}\right]$ state in fact has a distinctly lower energy. This error is of course not limited to the $C_{2 v}$ limit but remains over the entire saddling curve. The relative CASPT2 energies shown in Table 3 could be obtained with statespecific orbitals. The adiabatic energy differences between the minima of the ${ }^{3} \mathrm{~A}\left[\mathrm{Cu}^{\mathrm{II}}\right]$ and ${ }^{1} \mathrm{~A}\left[\mathrm{Cu}^{\mathrm{II}}\right]$ given in this table are lower by $5 \mathrm{kcal} / \mathrm{mol}$ than the differences found from the plots in Figure 3.

As one can see from Figure 3, the saddling distortion gives rise to a steep energy increase of the closed-shell ${ }^{1} \mathrm{~A}$ state obtained from CASPT2, while the open-shell ${ }^{1} \mathrm{~A}$ state is lowered in energy. The CASPT2 curves show a crossing of both states already at a small $\Omega$-angle: around $2.5^{\circ}$. Of course, crossing between these two states is in fact symmetry-forbidden and should therefore rather be avoided. In order to provide a better description of avoided crossings, the multistate (MS) option was implemented more than 10 years ago as an extension to the CASPT2 method. ${ }^{85}$ In this method, an effective Hamiltonian matrix is built where the diagonal elements are the CASPT2 energies and the off-diagonal elements take into account the coupling between both states under the influence of dynamic correlation. However, more recently this method was shown to fail, that is, strongly overestimate the energetic effect of the coupling, in cases where the effect of dynamic correlation is profoundly different for both states (thus giving rise to strongly asymmetric off-diagonal elements in the

(85) Finley, J.; Malmqvist, P.-Å.; Roos, B. O.; Serrano-Andrés, L. Chem. Phys. Lett. 1998, 288, 299-306. 
effective Hamiltonian matrix). ${ }^{86}$ This is clearly the case here, the open-shell ${ }^{1} \mathrm{~A}\left[\mathrm{Cu}^{\mathrm{II}}\right]$ state being described comparatively much better at the CASSCF level than the closed-shell ${ }^{1} \mathrm{~A}\left[\mathrm{Cu}^{\mathrm{III}}\right]$ state. The full set of saddling distortion curves for both singlet states as obtained from CASSCF, CASPT2, and MS-CASPT2 is included in the Supporting Information (Table S5). As one can see there, the MS-CASPT2 curves strongly exaggerate the energetic effect of the interaction between both states giving, instead of an avoided crossing, two curves that are driven apart by as much as $35 \mathrm{kcal} / \mathrm{mol}$ at the crossing point. We therefore decided not to consider the MS-CASPT2 results as relevant and to include only the CASPT2 curves in Figure 3. Of course, these curves do not provide the final answer and should be considered as qualitative, in particular, in the region close to the crossing point.

It is also important to note that, except for the $C_{2 v}$ structures, the states denoted by ${ }^{1} \mathrm{~A}\left[\mathrm{Cu}^{\mathrm{III}}\right]$ obtained from CASPT2 (Table 3, Figure 3) and from DFT (Table 3, Figure 2) do not describe the same electronic situation, even if they are given the same label. In the ${ }^{1} \mathrm{~A}\left[\mathrm{Cu}^{\mathrm{III}}\right]$ state obtained with CASPT2, the $\mathrm{Cu} 3 \mathrm{~d}_{x^{2}-y^{2}}$ orbital is essentially only involved in $\sigma$ type interaction with $\mathrm{N} \mathrm{p} \sigma$ orbitals of the corrole ligand. As this state does not gain from favorable $\sigma-\pi$ interactions, its energy rapidly rises upon saddling and, at the $C_{2}$ minimum ${ }^{1} \mathrm{~A}\left[\mathrm{Cu}^{\mathrm{III}}\right]$ becomes an excited state. On the other hand, with DFT the state denoted as ${ }^{1} \mathrm{~A}\left[\mathrm{Cu}^{\mathrm{III}}\right]$ corresponds to a spin-restricted description of the lowest singlet state that may (with hybrid functionals) or may not (with pure functionals) be stabilized further by giving up the spin-restriction. However, in both cases, this state obviously gains from saddling, due to the mixing between $\mathrm{Cu} 3 \mathrm{~d}_{x^{2}-y^{2}}$ and corrolate $\pi$ character. This explains the different energy landscape observed for the ${ }^{1} \mathrm{~A}\left[\mathrm{Cu}^{\mathrm{III}}\right]$ state in Figures 2 and 3 .

In Table 3, we have included the results for the structures and relative energies of the three states obtained from CASPT2 and RASPT2 (energies obtained with statespecific orbitals at the minima of the curves in Figure 3). The structures were taken from PBE0 (RDFT for both ${ }^{1} \mathrm{~A}$ states) with only $\Omega$ reoptimized, and one can see that the optimum CASPT2 saddling angle of the ${ }^{1} \mathrm{~A}\left[\mathrm{Cu}^{\mathrm{II}}\right]$ state, $5.70^{\circ}$ and $7.06^{\circ}$ for $\mathrm{Cu}(\mathrm{C})$ and $\mathrm{Cu}(\mathrm{TPC})$, respectively, indeed more closely corresponds to the $\Omega$-values obtained from the restricted (closed-shell ${ }^{1} \mathrm{~A}\left[\mathrm{Cu}^{\mathrm{III}}\right]$ ) DFT treatments than to the unrestricted (open-shell ${ }^{1} \mathrm{~A}\left[\mathrm{Cu}^{\mathrm{II}}\right]$ ) results obtained with the pure functionals. That lower CASPT2 energies are obtained for the $C_{2}{ }^{1} \mathrm{~A}\left[\mathrm{Cu}^{\mathrm{II}}\right]$ ground state when employing restricted rather than unrestricted PBE0 structures is primarily related to the shorter $\mathrm{Cu}-\mathrm{N}$ distances obtained from the restricted treatment. The experimental numbers included in Table 3 were taken from XRD experiments on $\mathrm{Cu}(\mathrm{TPC}),{ }^{27}$ and one can see that these numbers show a very close correspondence to the CASPT2 (and restricted PBE0) data, thus confirming the quality of the calculated results. For the triplet state, the CASPT 2 curves in Figure 3 confirm the observations made from DFT, predicting a planar structure for $\mathrm{Cu}(\mathrm{C})$ and a limited saddling for $\mathrm{Cu}(\mathrm{TPC})$.

(86) Serrano-Andrés, L.; Merchán, M.; Lindh, R. J. Chem. Phys. 2005, 122, 104107.
Considering the relative energies, we note that Figure 3 seems to point to the occurrence of a double minimum in the ground state ${ }^{1} \mathrm{~A}$ curve of both molecules. For $\mathrm{Cu}(\mathrm{C})$, the CASPT2/RASPT2 results even suggest a planar structure, with the $C_{2}$ minimum situated a few $\mathrm{kcal} / \mathrm{mol}$ higher in energy, whereas for $\mathrm{Cu}(\mathrm{TPC})$ the situation is reversed, the $C_{2}$ minimum now more stable by around $3 \mathrm{kcal} / \mathrm{mol}$ than the planar structure. Whether or not the barrier between these two minima would persist after properly accounting for the interaction and avoided crossing between both ${ }^{1} \mathrm{~A}$ curves is unclear at the moment. As for the adiabatic relative energy of the lowest triplet state ${ }^{3} \mathrm{~A}$ with respect to the ${ }^{1} \mathrm{~A}$ ground state, we find that (similar to the $C_{2 v}$ results; see previous section) RASPT2 systematically predicts a smaller splitting (by $3.5-5.5 \mathrm{kcal} / \mathrm{mol}$ ) than CASPT2. Both numbers more closely correspond to the results obtained with the pure functionals OLYP and BP86 than with the hybrid functionals PBE0 and B3LYP. Taking into account thermodynamic corrections would slightly lower the splittings reported in Table 3 by around $1 \mathrm{kcal} / \mathrm{mol}^{81}$ bringing the "best" RASPT2 result for $\mathrm{Cu}(\mathrm{TPC}), 7.4 \mathrm{kcal} / \mathrm{mol}$, close to the experimental number of $5.8 \mathrm{kcal} / \mathrm{mol}$ reported from variable temperature NMR measurements on $\beta$-octaethyl-5,15-diphenylcorrole. ${ }^{22}$

3.3. Diradical Character of the Singlet Ground State. The formal oxidation state of a given metal ion in a mononuclear coordination compound is a nonmeasurable integer which is commonly defined as the charge left on the metal after all ligands have been removed in their normal, closed-shell configuration, that is with their electron pair. ${ }^{72}$ In the absence of exogenous ligands, the formal oxidation state of copper corroles is $(+3)$, bound to a trianionic corrolate. In practice, electron donaton from the corrolate into the (formally empty) $\mathrm{Cu} \mathrm{d}_{x^{2}-y^{2}}$ orbital gives rise to a much smaller effective charge. Electron donation may be accomplished by two alternative interaction types: (a) a dative two-electron bond from the corrolate to the $\mathrm{Cu}^{\mathrm{III}}$ ion, providing covalent character to the (otherwise fully ionic) copper-corrolate bond. This interaction type may be adequately described by a single closed-shell determinant with all electrons paired but delocalized over the $\mathrm{Cu} 3 \mathrm{~d}_{x^{2}-y^{2}}$ and corrole $\sigma$ and $\pi$ orbitals (belonging to the same symmetry representation); (b) transfer of an entire electron from the corrolate trianion into $3 \mathrm{~d}_{x^{2}-y^{2}}$, turning the $\mathrm{Cu}^{\text {III }}-$ corrolate $^{3-}$ system into a $\mathrm{Cu}^{\text {II }}-$ corrolate $^{\bullet 2-}$ diradical, and the corrole into a noninnocent ligand. Bonding copper-corrole interaction then arises from antiferromagnetic exchange coupling between the two unpaired spins which, although now spatially separated, should reside in orbitals that are at least weakly overlapping.

Obviously, the distinction between both interaction types is not absolute. The above descriptions are just extremes of a continuum of possibilities. The two extremes are easily described in MO terms as closed-shell and open-shell singlet configurations, respectively. Only the closed-shell extreme may be described by a restricted single-determinant HF or DFT treatment. The open-shell case, as well as all intermediate situations, can only be handled by either a multideterminantal wave function or by a spin-unrestricted approach.

The above concepts may be illustrated by considering the ground state wave function obtained from a CASSCF 
(A)
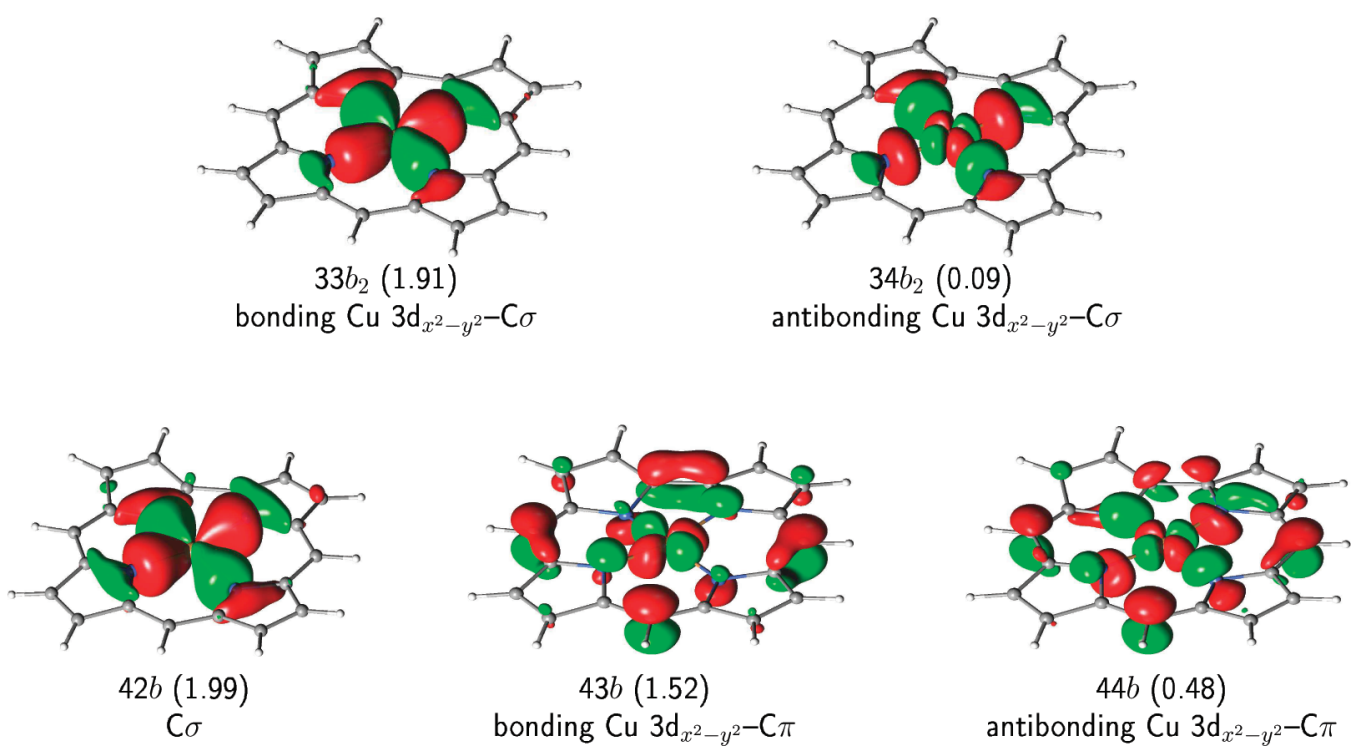

Figure 4. $\mathrm{CASSCF}(12 \mathrm{in} 13)$ natural orbitals involved in the $\mathrm{Cu}$-corrole bond formation in $\mathrm{Cu}(\mathrm{C})$. (A) Planar stucture $\left(C_{2 v}\right)$; (B) saddled structure $\left(C_{2}\right)$. Occupation numbers are given within parentheses. The contour values are $\pm 0.04 \mathrm{e} / \mathrm{au}^{3}$.

calculation for the planar and saddled structures of either of the considered copper corroles. A plot of the most important natural orbitals (NO) involved in the coppercorrole interaction in $\mathrm{Cu}(\mathrm{C})$ (obtained from CAS (12in13)), together with their occupation numbers (NOON), is provided in Figure 4. In the planar corrole, charge transfer into the copper $3 \mathrm{~d}_{x^{2}-y^{2}}$ orbital is (for symmetry reasons) limited to $\sigma$-donation involving the nitrogen lone pairs $\mathrm{N}$ $\mathrm{p} \sigma$. Expressed in terms of its natural orbitals, the ground state wave function of this $C_{2 v}$ structure has one major term, that is, the HF closed-shell determinant appearing with a weight of $91 \%$. The second most important term has a weight of $4 \%$ and corresponds to a double excitation from the bonding into the antibonding $\mathrm{Cu} 3 \mathrm{~d}_{x^{2}-y^{2}}-$ corrole $\sigma$ combination. Both NOs are shown in Figure 4A. They both show extensive mixing of $\mathrm{Cu} 3 \mathrm{~d}$ and corrole $\sigma$ character, indicating a strongly covalent $\mathrm{Cu}-\mathrm{N} \sigma$ bond. The dominance of the closed-shell HF configuration is reflected in the NOON, 1.91 for the bonding and only 0.09 for the antibonding orbital. Going to the saddled $C_{2}$ structure, we again find a ground state wave function with only two important terms. However, the weight of the HF configuration is now reduced to $74 \%$, at the expense of the doubly excited configuration, obtaining a weight $23 \%$. As can be seen from Figure 4B, the character of the NOs involved in the excitation is also thoroughly different from the $C_{2 v}$ situation, at least as the corrole part is concerned, consisting now of predominant $\pi$ rather than $\sigma$ character. Inspection of the NOON of the involved orbitals shows that now half an electron is transferred from the bonding to the antibonding $\mathrm{Cu} 3 \mathrm{~d}_{x^{2}-y^{2}}$-corrole $\pi$ combination. The (predominantly) corrole $\sigma$ orbital is also included in the figure. As compared to its $C_{2 v}$ analogue, this orbital has now virtually lost all $\mathrm{Cu} 3 \mathrm{~d}$ character, while at the same time its occupation number, 1.99 , has moved significantly closer to two.

The difference in multideterminantal composition between these two wave functions $(91 \% / 4 \%$ versus $74 \%$ / $23 \%$ ) is certainly not dramatic. Still, at least at first sight both wave functions seem to represent a thoroughly different type of copper-corrole interaction. For the planar structure, we can all almost certainly agree that the corrole ligand is innocent but engaged in strongly covalent $\sigma$ type interactions with the high-valent $\mathrm{Cu}^{\mathrm{III}}$ ion. On the other hand, in the saddled structure, the fact that (i) in Figure 3 the $C_{2}$ ground states obviously correlates to the openshell ${ }^{1} \mathrm{~A}_{2}$ state in $C_{2 v}$; (ii) the $\mathrm{Cu} 3 \mathrm{~d}_{x^{2}-y^{2}}$ and corrole $\pi$ orbitals are spatially well-separated; and (iii) the wave function has considerable multiconfigurational character rather seems to point to an noninnocent copper corrole, that is, $S=1 / 2 \mathrm{Cu}^{\mathrm{II}}$ strongly antiferromagnetically coupled to a corrolate ${ }^{2-}$ radical. As a matter of fact, a strict verdict "noninnocent" was given to corrole in a very similar bonding situation, as it occurs in chloroiron corrole. ${ }^{24}$ In this molecule, the central iron is formally $\mathrm{Fe}^{\mathrm{IV}}$ and the ground state is a triplet corresponding to the configuration $\mathrm{d}_{x y}{ }^{2} \mathrm{~d}_{x z}{ }^{1} \mathrm{~d}_{y z}{ }^{1} \cdot 23,24$ However, analysis of the NO originating from a CASSCF calculation shows the occurrence of two $\mathrm{NO}$ with occupation numbers that strongly deviate from either two or zero. They are the bonding and antibonding combinations of $\mathrm{Fe} 3 \mathrm{~d}_{z^{2}}$ and the corrole $\pi$ HOMO orbital and are occupied by 1.42 and 0.59 electrons, respectively. Interaction between these two orbitals becomes possible because the iron atom is located out of the corrole plane. The noninnocent verdict was based on a localization procedure, transforming the two NOs into two orbitals that are either completely localized on iron $\left(\mathrm{d}_{z^{2}}\right)$ or corrole $(\operatorname{HOMO} \pi)$. Such a procedure does not affect the overall ground state wave function and its energy. However, when expressed in terms of the localized orbitals, the wave function becomes essentially monoconfigurational, with a spin-up electron in $\mathrm{Fe} \mathrm{d}_{z^{2}}$ coupled to a spin-down electron in the corrole $\pi$ orbital (and vice versa). The result of this analysis was claimed to prove unequivocally that chloroiron corrole is noninnocent, with $S=3 / 2 \mathrm{Fe}^{\mathrm{III}}$ antiferromagnetically coupled to a corrolate ${ }^{\bullet 2-}$ radical.

In this work, we have used the same localization procedure on $\mathrm{Cu}(\mathrm{C})$ as was done previously for chloroiron corrole, ${ }^{24}$ both for the planar and the saddled structures. 
(A)

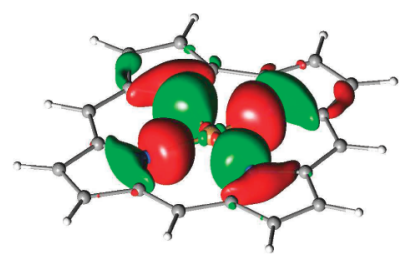

$\mathrm{C} \sigma$

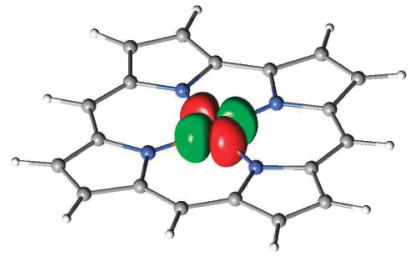

$\mathrm{Cu} 3 \mathrm{~d}_{x^{2}-y^{2}}$

(B)

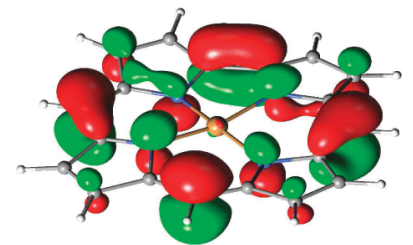

$\mathrm{C} \pi$

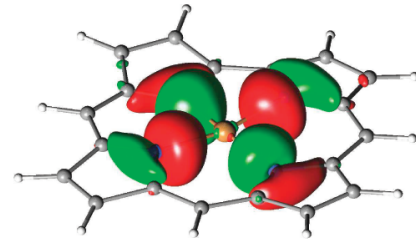

$\mathrm{C} \sigma$

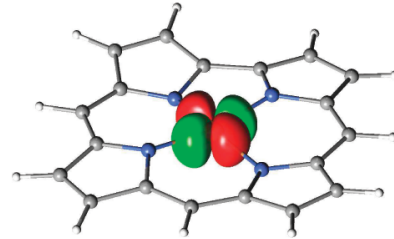

$\mathrm{Cu} 3 \mathrm{~d}_{x^{2}-y^{2}}$

Figure 5. Localized orbitals (obtained from the $\mathrm{CASSCF}(12$ in13) natural orbitals in Figure 4) involved in the $\mathrm{Cu}-\mathrm{corrole}$ bond formation in $\mathrm{Cu}(\mathrm{C})$. (A) Planar stucture $\left(C_{2 v}\right)$; (B) saddled structure $\left(C_{2}\right)$. The contour values are $\pm 0.04 \mathrm{e} / \mathrm{au}^{3}$.

The resulting localized orbitals are shown in Figure 5. With these orbitals, the ground state wave function in the planar structure has the following main constituents (C standing for corrole, $\mathrm{C} \pi$ doubly occupied in all three terms in eq 4):

$$
\begin{gathered}
\text { planar } \rightarrow 20 \%(\mathrm{C} \sigma)^{2}\left(\mathrm{Cu} 3 \mathrm{~d}_{x^{2}-y^{2}}\right)^{0} ; \\
65 \%(\mathrm{C} \sigma)^{\uparrow}\left(\mathrm{Cu} 3 \mathrm{~d}_{x^{2}-y^{2}}\right)^{\downarrow} ; 10 \%(\mathrm{C} \sigma)^{0}\left(\mathrm{Cu} 3 \mathrm{~d}_{x^{2}-y^{2}}\right)^{2}
\end{gathered}
$$

while for the saddled structure we find:

$$
\begin{gathered}
\text { saddled } \rightarrow 2 \%(\mathrm{C} \sigma)^{2}(\mathrm{C} \pi)^{2}\left(\mathrm{Cu} 3 \mathrm{~d}_{x^{2}-y^{2}}\right)^{0} ; \\
68 \%(\mathrm{C} \sigma)^{2}(\mathrm{C} \pi)^{\uparrow}\left(\mathrm{Cu} \mathrm{3} \mathrm{d}_{x^{2}-y^{2}}\right)^{\downarrow} ; \\
11 \%(\mathrm{C} \sigma)^{\uparrow}(\mathrm{C} \pi)^{2}\left(\mathrm{Cu} \mathrm{3} \mathrm{d}_{x^{2}-y^{2}}\right)^{\downarrow} ; \\
13 \%(\mathrm{C} \sigma)^{\uparrow}(\mathrm{C} \pi)^{\downarrow}\left(\mathrm{Cu} \mathrm{d} x_{x^{2}-y^{2}}\right)^{2} ; \\
2 \%(\mathrm{C} \sigma)^{0}(\mathrm{C} \pi)^{2}\left(\mathrm{Cu} \mathrm{3} \mathrm{d}_{x^{2}-y^{2}}\right)^{2}
\end{gathered}
$$

The first term of both equations is purely ionic $\mathrm{Cu}^{\mathrm{III}}$ corrolate $^{3-}$. This term quite significantly contributes to the copper-corrole $\sigma$-interaction in planar $\mathrm{Cu}(\mathrm{C})$. It is also interesting to see that the localization procedure even points to a significant contribution $(10 \%$ in the planar, $15 \%$ in the saddled structure) of term(s) corresponding to $\mathrm{Cu} 3 \mathrm{~d}^{10}$, thus representing a $\mathrm{Cu}^{\mathrm{I}}-$ corrolate $^{1-}$ ionic contribution. The most important contribution to both wave functions comes from the remaining "neutral" term(s). However, obviously "neutral" here stands for either covalent (dative) or diradical or for a mixture of both (otherwise, one would have to accept that the $\mathrm{Cu} 3 \mathrm{~d}_{x^{2}-y^{2}}$ corrole $\sigma$ bond in planar corrole is of diradical nature). The wave function obtained from the localization procedure does not distinguish between covalent and diradical contributions. We therefore cannot go along with the conclusion from ref 24 that such a wave function unequivocally points to a noninnocent corrole, not for the present copper corroles and also not for chloroiron corrole.

An alternative, conceptually very simple definition of diradical character of a particular bond $i$ is based on the
Table 4. NOON, $\left\langle S^{2}\right\rangle^{\mathrm{BS}}$ and Diradical Character of Saddled $\mathrm{Cu}(\mathrm{C})$ and $\mathrm{Cu}(\mathrm{TPC})$ According to Different Computational Approaches

\begin{tabular}{lccccc}
\hline & $n_{+}$ & $n_{-}$ & $Y$ & $\left\langle S^{2}\right\rangle^{\mathrm{BS}}$ & $Y_{\text {cor }}$ \\
\hline \multicolumn{7}{c}{$\mathrm{Cu}(\mathrm{C})$} \\
PBE0 & 1.18 & 0.82 & 0.82 & 0.999 & 0.65 \\
B3LYP & 1.35 & 0.65 & 0.65 & 0.899 & 0.38 \\
CASSCF & 1.50 & 0.50 & 0.50 & \\
& \multicolumn{7}{c}{$\mathrm{Cu}(\mathrm{TPC})$} \\
PBE0 & 1.39 & 0.61 & 0.61 & 0.877 & 0.33 \\
B3LYP & 1.49 & 0.51 & 0.51 & 0.778 & 0.21 \\
CASSCF & 1.53 & 0.47 & 0.47 & &
\end{tabular}

NOON of the two orbitals involved in the bond. ${ }^{37,87}$ The effective bond order $b_{i}$ is defined by

$$
b_{i}=\frac{n^{+}-n^{-}}{2}
$$

with $n^{+}$and $n^{-}$representing the NOON of the bonding and antibonding molecular orbital involved. As indicated by Figure 4, these numbers add up to (roughly) two. $b_{i}$ becomes 1.0 in the closed-shell case, whereas $b_{i}$ is 0.0 for a pure singlet diradical. The diradical character $Y_{i}$ may therefore be defined as

$$
Y_{i}=1-b_{i}
$$

On the basis of this definition and using the CAS(12in13) wave function, we obtain a diradical character of $50 \%$ for saddled $\mathrm{Cu}(\mathrm{C})$, while for planar $\mathrm{Cu}(\mathrm{C})$ this is only $10 \%$. For $\mathrm{Cu}$ (TPC), the same small diradical character is obtained for the planar structure, while for the saddled structure a diradical character of $47 \%$ is found, $3 \%$ less than for $\mathrm{Cu}(\mathrm{C})$. The latter may be related to the fact that the $\mathrm{Cu}$ (TPC) structure is more profoundly saddled (see Figure 2), thus giving rise to stronger antiferromagnetic coupling and concomitant increase in closed-shell

(87) Takano, Y.; Taniguchi, T.; Isobe, H.; Kubo, T.; Morita, Y.; Yamamoto, K.; Nakasuji, K.; Takui, T.; Yamaguchi, K. Chem. Phys. Lett. 2002, 358, 17-23. 


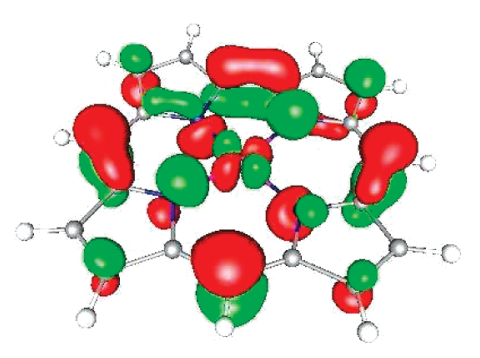

$43 b(1.35)$ bonding $\mathrm{Cu} 3 \mathrm{~d}_{x^{2}-y^{2}}-\mathrm{C} \pi$

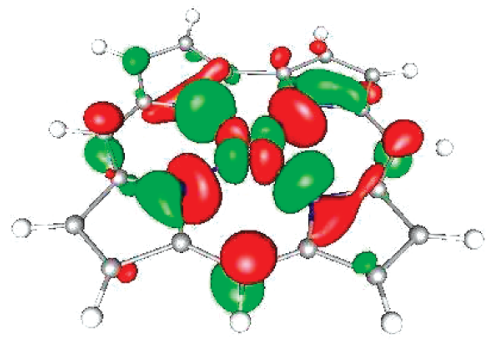

$44 b(0.65)$

antibonding $\mathrm{Cu} 3 \mathrm{~d}_{x^{2}-y^{2}}-\mathrm{C} \pi$

Figure 6. Natural orbitals and their occupation numbers (within parentheses) obtained from the unrestricted B3LYP calculation on the $C_{2}$ ground state of $\mathrm{Cu}(\mathrm{C})$. Only the two NOs with occupation numbers (significantly) different from either two or zero are shown. The contour values are \pm 0.04 e/au ${ }^{3}$.

character. We also note that, based on the NOON of the bonding and antibonding combinations of $\mathrm{Fe} 3 \mathrm{~d}_{z^{2}}$ and the corrole $\pi$ HOMO orbital in chloroiron corrole, ${ }^{24}$ the iron-corrole bond in this molecule is predicted to be $59 \%$ diradical.

The above definition of diradical character also forms an interesting conceptual bridge between the DFT and multiconfigurational approaches employed in this work. Table 4 includes the occupation numbers obtained from PBE0 and B3LYP for the (only) two natural orbitals with occupations (significantly) different from two or zero. Obviously, for the restricted closed-shell determinant obtained from either BP86 and OLYP the diradical character is strictly zero. A plot of the natural orbitals obtained from B3LYP for $\mathrm{Cu}(\mathrm{C})$ is shown in Figure 6. One can see that these orbitals closely resemble the CASSCF natural orbitals in Figure 4. The diradical character obtained from the DFT NOON is significantly larger than the corresponding CASSCF value. This is of course at least partly due to the presence of a considerable amount of triplet character in the unrestricted DFT solutions. After correcting for spin contamination, ${ }^{37,88,89}$ a spinprojected effective bond order $B_{i}$ is obtained as

$$
B_{i}=\frac{2 b_{i}}{1+b_{i}^{2}} \geq b_{i}
$$

The corrected diradical character $Y_{\mathrm{cor}, i}$ is then given by

$$
Y_{\text {cor }, i}=1-B_{i}
$$

As can be seen from Table 4 after correcting for spin contamination, the diradical character predicted by DFT is strongly reduced. With B3LYP, the ground state becomes predominantly closed-shell for both molecules, whereas PBE0 still gives $65 \%$ diradical character to $\mathrm{Cu}(\mathrm{C})$, but only $33 \%$ to $\mathrm{Cu}$ (TPC). The most striking difference between the numbers obtained from CASSCF and DFT is that the ground state electronic wave function obtained from the former method seems to be much less affected by the presence of phenyl substituents in $\mathrm{Cu}(\mathrm{TPC})$ as compared to $\mathrm{Cu}(\mathrm{C})$, only increasing its diradical contribution by a few $\%$. With DFT, the differences between both

(88) Shoji, M.; Nishiyama, Y.; Maruno, Y.; Koizumi, K.; Kitagawa, Y.; Yamanaka, S.; Kawakami, T.; Okumara, M.; Yamaguchi, K. Int. J. Quant. Chem. 2004, 100, 887-906.

(89) Shoji, M.; Hamamoto, T.; Koizumi, K.; Isobe, H.; Kitagawa, Y.; Takano, Y.; Yamanaka, S.; Okumura, M.; Yamaguchi, K. Polyhedron 2005, 24, 2701-2707. molecules are much larger, both before and after correcting for spin contamination.

\section{Conclusions}

The present contribution on $\mathrm{Cu}(\mathrm{C})$ and $\mathrm{Cu}(\mathrm{TPC})$ confirms the conclusions from previous DFT studies that copper corroles are inherently saddled ${ }^{25}$ and that the driving force for the saddling is the possibility for attractive $\sigma-\pi$ interactions between the $\mathrm{Cu} 3 \mathrm{~d}_{x^{2}-y^{2}}$ and $b_{1}$ type corrolate HOMO orbitals. ${ }^{22}$ These orbitals are orthogonal in the planar $\left(C_{2 v}\right)$ structures but are given the opportunity to mix by saddling. However, we have shown here that the concrete description of the ground state electronic structure of these complexes heavily depends on the computational approach. In particular, with DFT pure functionals (BP86, OLYP) predict a closed-shell ground state with strongly covalent coppercorrolate bonds, of pure $\sigma$ type in the planar structure, but with strongly mixed $\sigma-\pi$ character in the saddled structures. On the other hand, hybrid functionals (B3LYP, PBE0) predict an open-shell singlet ground state with pronounced diradical character, built from magnetic exchange coupling between two unpaired spins in either $\mathrm{Cu} 3 \mathrm{~d}_{x^{2}-y^{2}}$ and the $b_{1}$ type corrolate HOMO. In the planar structures, the coupling is ferromagnetic (as both orbitals are orthogonal), but it turns to antiferromagnetic upon saddling, with an increasing contribution of closed-shell character as the saddling becomes more pronounced.

The present contribution presents the first multiconfigurational study of the electronic structure of these peculiar compounds. The CASSCF calculations undoubtedly provide a more rigorous and complete picture of the relationship between the geometrical and electronic ground state structure than DFT, by presenting a two-state description of the saddling phenomenon. The two states involved are (essentially) (a) a closed-shell singlet state characterized by covalent (dative) $\sigma$ bonding between the corrolate $\mathrm{N} \mathrm{p} \sigma$ lone pairs and $\mathrm{Cu}$ $3 \mathrm{~d}_{x^{2}-y^{2}}$, and (b) an open-shell singlet state displaying $\sigma-\pi$ interaction between two unpaired electrons in $\mathrm{Cu} 3 \mathrm{~d}_{x^{2}-y^{2}}$ and the corrolate $b_{1} \pi$ orbital. The latter interaction may essentially be described as diradical, although it also has a significant (at most 50\%) covalent contribution. The closedshell singlet is the ground state in the planar structures. Because of the absence of $\sigma-\pi$ interaction, this state shows no tendency to distort from planarity and is raised in energy upon saddling. On the other hand (and conform to B3LYP and PBE0), the open-shell singlet state is stabilized by saddling due to an increasing overlap between both orbitals 
involved in the exchange interaction. At the CASSCF/ CASPT2 level, both states cross already at a small saddling angle. Unfortunately, the interaction between both states that should result in their avoided crossing cannot be treated properly by the MS-CASPT2 algorithm that is presently implemented in the MOLCAS code.

The presence of a low-lying triplet state, observed by variable temperature NMR, is confirmed in this study at all computational levels. The state concerned is the ferromagnetic alternative to the open-shell singlet state. Its relative energy as compared to the diamagnetic ground state is, as compared to the experimental $\Delta H$ value of $5.8 \mathrm{kcal} / \mathrm{mol}$ for $\beta$-octaethyl-5,15-diphenylcorrole, best reproduced by the results obtained by means of RASPT2, predicting an electronic energy difference of $3.8 \mathrm{kcal} / \mathrm{mol}$ for $\mathrm{Cu}(\mathrm{C})$ and $7.4 \mathrm{kcal} / \mathrm{mol}$ for $\mathrm{Cu}(\mathrm{TPC})$. Making use of the computational experience obtained from the present work, we are presently performing a more detailed study of substituent effects on the saddling distortion and the triplet-singlet splitting in a series of substituted copper corroles. ${ }^{81}$

Acknowledgment. This investigation has been supported by grants from the Flemish Science Foundation (FWO) and from the Concerted Research Action of the Flemish Government (GOA). S.V. thanks the University of Leuven (BOF) for financial support.

Supporting Information Available: Figures S1-S5. This material is available free of charge via the Internet at http://pubs. acs.org. 